\title{
Operating charts for continuous sedimentation III: control of step inputs
}

\author{
STEFAN DIEHL \\ Centre for Mathematical Sciences, Lund University, P.O. Box 118, SE-221 00 Lund, Sweden (e-mail: \\ diehl@maths.lth.se)
}

\begin{abstract}
The main purposes of a clarifier-thickener unit is that it should produce a high underflow concentration and a zero effluent concentration. The main difficulty in the control of the clarification-thickening process (by adjusting a volume flow) is that it is non-linear with complex relations between concentrations and volume flows via the solution of a PDE - a conservation law with a source term and a space-discontinuous flux function. In order to approach this problem, control objectives for dynamic operation and strategies on how to meet these objectives are presented in the case when the clarifier-thickener unit initially is in steady state in optimal operation and is subjected to step input data. A complete classification of such solutions is given by means of an operating chart (concentration-flux diagram).
\end{abstract}

Keywords: operating charts, continuous sedimentation, control, thickener, step response

Received xxxxx

\section{Introduction}

The process of continuous sedimentation of particles in a liquid has received considerable interest during the last century. There are many publications in the range from experiments to rigorous mathematical modelling. For many purposes simplified one-dimensional models are mostly considered and wanted for simulation, control and design of plants. We refer to the previous papers in this series $[1,2]$ for references and discussions of previous works. For the particular problem of controlling the process, different angles of approach can be found in [3-9].

The one-dimensional model for an ideal clarifier-thickener can be written as a partial differential equation that conserves the mass (conservation law). There are different types of modelling problems that arise. One is the settling and compressible behaviour of the particles, reflected in the constitutive relation between the settling flux (mass per time and area unit) and the concentration and other physical variables. Other problems are the mathematical difficulties that arise due to the discontinuities of the flux function at the inlet and outlets of the sedimentation vessel. In [1, 2], it was motivated why it is important to continue to examine all consequences of the fundamental constitutive assumption by Kynch, although it does not take into account the compressible behaviour for high concentrations that many suspensions show. A further motivation for the present paper is that a systematic analysis of the control possibilities and limitations of the process cannot be found in the literature.

The aim of the present series of articles is to give a deeper knowledge of the continuoussedimentation process for all possible input data and to present how the process can be controlled. This is done by classifying the non-linear behaviour by means of operating charts. In [1], all qualitatively different steady-state solutions and several relations between the different variables were presented. Control objectives were also suggested. Since the process is hardly 
ever in complete steady state, it is not sufficient to have control objectives formulated only in terms of steady-state solutions. In [2], the state of optimal operation was defined as a class of a dynamic solution. Furthermore, all qualitatively different step responses were classified in the case when the settler is in optimal operation initially and the control variable (the volume underflow rate) is held constant. The same initial conditions are assumed in the present paper and all theoretically possible step inputs are considered. In addition, the control variable is now adjusted.

The paper is organized as follows. Sections 2 and 3 contain the necessary previous results and notation. Control objectives for dynamic solutions are formulated in Section 4 and strategies on how to satisfy these are introduced in Section 5. A control strategy is called optimal if the given control objective is satisfied. To establish optimal control strategies, the first step is to investigate dynamic solutions when there is a direct control action (a step change in the control variable). These solutions are presented and classified in Section 6. Although the value of the control variable in each case corresponds to a desired steady-state solution, the control objectives are not satisfied in all cases. Hence, more advanced control strategies are needed to meet the control objectives. The main results of the paper are the optimal control strategies presented in Section 7.

\section{The clarifier-thickener unit and the model}

The one-dimensional model of the clarifier-thickener unit, or settler, was presented first in [10]. The model and the full notation for constructing solutions are given in [2, Section 2], to which we now refer the reader. Here, we review only briefly the basic concepts. Although we refer to analytical solutions of the model partial differential equation, the paper can be read without going into such details and by studying the operating charts and numerical solutions instead.

Figure 1 shows the settler together with the flux function in the thickening zone. The typical and desired steady-state solution has zero concentration in the clarification zone and a discontinuity in the thickening zone between the concentrations $u_{\mathrm{m}}$ and $u_{\mathrm{M}}$. This is called the sludge blanket level (SBL) in wastewater treatment and it is important to be able to control it. The conservation law can be written as the partial differential equation

$$
u_{t}+(F(u, x))_{x}=s(t) \delta(x),
$$

where the total flux function is

$$
F(u, x)= \begin{cases}-q_{\mathrm{e}} u, & x<-H \\ g(u)=f_{\mathrm{b}}(u)-q_{\mathrm{e}} u, & -H<x<0 \\ f(u)=f_{\mathrm{b}}(u)+q_{\mathrm{u}} u, & 0<x<D \\ q_{\mathrm{u}} u, & x>D,\end{cases}
$$

$\delta$ is the Dirac measure and the source function is

$$
s(t)=\frac{Q_{\mathrm{f}}}{A} u_{\mathrm{f}}(t)=\frac{Q_{\mathrm{u}}+Q_{\mathrm{e}}}{A} u_{\mathrm{f}}(t)=\left(q_{\mathrm{u}}+q_{\mathrm{e}}\right) u_{\mathrm{f}}(t) .
$$

The physical input variables are the feed concentration $u_{\mathrm{f}}$ and the feed volume flow $Q_{\mathrm{f}}$. For the graphical interpretations by means of operating charts it is, however, convenient to use the 

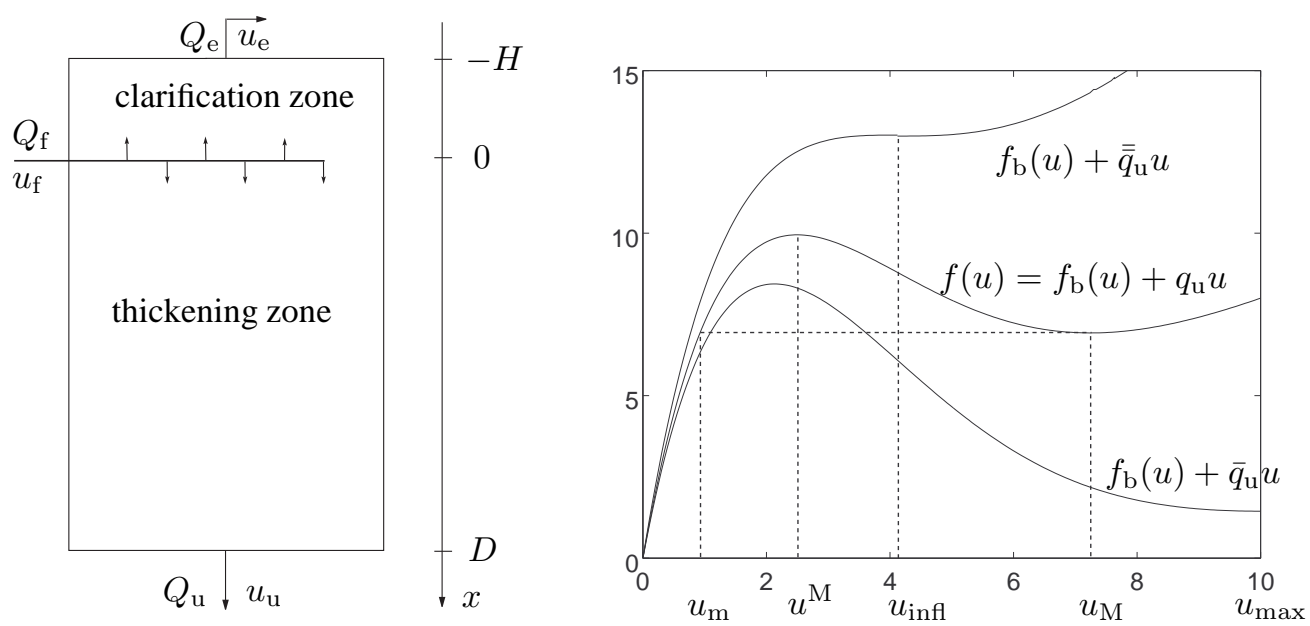

Figure 1. Left: Schematic picture of an ideal one-dimensional clarifier-thickener unit, where $u$ stands for concentration and $Q$ for volume flow of the feed, effluent and underflow streams, respectively. The flow restrictions are $Q_{\mathrm{f}}=Q_{\mathrm{e}}+Q_{\mathrm{u}}>0$ and $Q_{\mathrm{e}} \geq 0$. Right: Flux curves $f(u)$ in the thickening zone and characteristic concentrations. The bulk velocities are defined as $q_{\mathrm{u}}=Q_{\mathrm{u}} / A$ etc., where $A$ is the cross-sectional area. For $\bar{q}_{\mathrm{u}}<q_{\mathrm{u}}<\overline{\bar{q}}_{\mathrm{u}}$ there is a local minimum point $u_{\mathrm{M}}$ of $f(u)$ that lies between $u_{\text {inf }}$ and $u_{\max }$. Given $u_{\mathrm{M}}, u_{\mathrm{m}}$ is the lower concentration defined by $f\left(u_{\mathrm{m}}\right)=f\left(u_{\mathrm{M}}\right) . u^{\mathrm{M}}$ is the (local) maximum point of $f(u)$. $u_{\mathrm{inf}}$ is the inflection point of $f_{\mathrm{b}}(u)$ and $f(u)$ (independent of $q_{\mathrm{u}}$ ). The batch-settling flux used for the numerical simulations is $f_{\mathrm{b}}(u)=10 u\left(\left(1-0.64 u / u_{\max }\right)^{6.55}-0.36^{6.55}\right)\left[\mathrm{kg} /\left(\mathrm{m}^{2} \mathrm{~h}\right)\right]$.

feed point $\left(u_{\mathrm{f}}, s\right)$ as input variable. The control variable of the process is $Q_{\mathrm{u}}$. Two particular values of this variable arise from the properties of the batch settling flux function. Define

$$
\begin{array}{ll}
\bar{q}_{\mathrm{u}}=-f_{\mathrm{b}}^{\prime}\left(u_{\max }\right), & \bar{Q}_{\mathrm{u}}=\bar{q}_{\mathrm{u}} A, \\
\overline{\bar{q}}_{\mathrm{u}}=-f_{\mathrm{b}}^{\prime}\left(u_{\mathrm{infl}}\right), & \overline{\bar{Q}}_{\mathrm{u}}=\overline{\bar{q}}_{\mathrm{u}} A,
\end{array}
$$

which are the bulk velocities such that the slope of $f$ is zero at $u_{\max }$ and $u_{\text {infl }}$, respectively, see Figure 1 (right).

The purposes of the settler may vary depending on in what industrial process it is involved. At least in wastewater treatment the main purposes of the settler are the following. It should

1. produce a low effluent concentration.

2. produce a high underflow concentration.

3. work as a buffer of mass and be insensitive to small variations in the feed variables.

These purposes cannot be controlled independently.

\section{Control of steady states and optimal operation}

Figure 2 shows the operating chart for the steady states. Depending on the location of the feed point $\left(u_{\mathrm{f}}, s\right)$ in the steady-state chart there are different possible steady-state solutions, which are all piecewise constant and non-decreasing with depth, see [1] for a complete table and the 


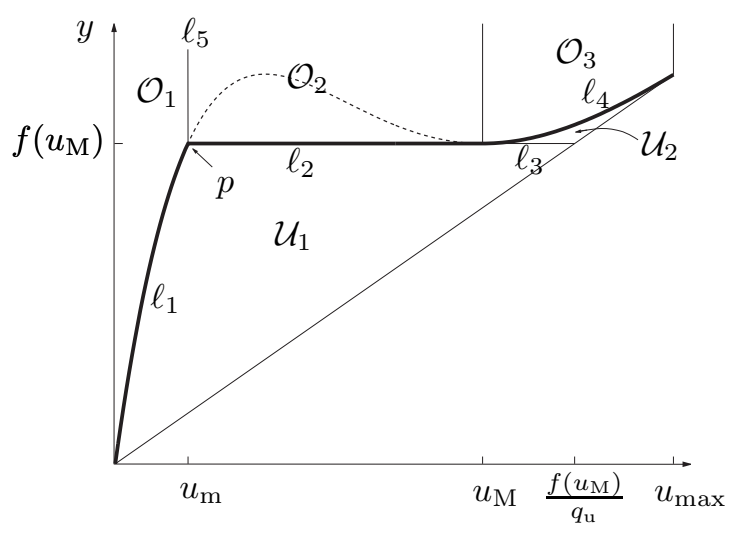

Figure 2. The steady-state chart. The thick graph is the limiting flux curve. If the feed point lies on this curve, the settler is critically loaded in steady state, which means that it works at its maximum capacity. Below this graph the settler is underloaded, and above it it is overloaded with a non-zero effluent concentration. Each region corresponds to a specific steady state, which is unique except on the limiting flux curve (and on $\ell_{3}$ and $\ell_{5}$ ), where the location of a discontinuity in the thickening and/or the clarification zone is not uniquely determined. Note that the regions in this chart all depend on $Q_{\mathrm{u}}$. (They are defined in [1].)

full notation. The limiting flux and the excess flux are defined as:

$$
\begin{aligned}
& f_{\lim }(u)=\min _{u \leq \alpha \leq u_{\max }} f(\alpha)= \begin{cases}f(u), & u \in\left[0, u_{\mathrm{m}}\right] \cup\left[u_{\mathrm{M}}, u_{\max }\right], \\
f\left(u_{\mathrm{M}}\right), & u \in\left(u_{\mathrm{m}}, u_{\mathrm{M}}\right),\end{cases} \\
& \mathcal{E}\left(u_{\mathrm{f}}, s\right)=s-f_{\lim }\left(u_{\mathrm{f}}\right) .
\end{aligned}
$$

These fluxes, as well as the characteristic concentrations and the regions of the steady-state chart depend on the control variable $Q_{\mathrm{u}}$; e.g. $u_{\mathrm{M}}\left(Q_{\mathrm{u}}\right), f\left(u, Q_{\mathrm{u}}\right), f_{\lim }\left(u_{\mathrm{f}}, Q_{\mathrm{u}}\right)$ and $\mathcal{E}\left(u_{\mathrm{f}}, s, Q_{\mathrm{u}}\right)$. The following regions in the operating chart are independent on $Q_{\mathrm{u}}$ :

$$
\begin{aligned}
\Lambda_{i} & =\bigcup_{Q_{\mathrm{u}}>0} \ell_{i}\left(Q_{\mathrm{u}}\right), \quad i=1, \ldots, 4, \\
P & =P_{1} \cup P_{2}, \quad \text { where } \quad P_{1}=\bigcup_{0<Q_{\mathrm{u}} \leq \bar{Q}_{\mathrm{u}}} p\left(Q_{\mathrm{u}}\right), \quad P_{2}=\bigcup_{Q_{\mathrm{u}}>\bar{Q}_{\mathrm{u}}} p\left(Q_{\mathrm{u}}\right),
\end{aligned}
$$

see Figure 3 (right). In [1] some control objectives are formulated in order to meet the five purposes stated in Section 2. It turns out that it is important to be able to have a critically loaded settler in steady state, i.e., to find a value of $Q_{\mathrm{u}}$ such that $\mathcal{E}\left(u_{\mathrm{f}}, s, Q_{\mathrm{u}}\right)=0$. The following theorem in [1] captures the most important properties in this context.

THEOREM 3.1. Given $\left(u_{\mathrm{f}}, s\right) \in\left\{(u, y): 0<u \leq u_{\max }, y>0\right\}$ there exists a unique $\tilde{Q}_{\mathrm{u}}\left(u_{\mathrm{f}}, s\right)>0$ such that $\mathcal{E}\left(u_{\mathrm{f}}, s, \tilde{Q}_{\mathrm{u}}\right)=0$ and the following properties hold:

$$
\begin{aligned}
& \left(u_{\mathrm{f}}, s\right) \in \Lambda_{i} \quad \Longrightarrow \quad\left(u_{\mathrm{f}}, s\right) \in \ell_{i}\left(\tilde{Q}_{\mathrm{u}}\right), \quad i=1,2,4, \\
& \left(u_{\mathrm{f}}, s\right) \in P \quad \Longrightarrow \quad\left(u_{\mathrm{f}}, s\right) \in p\left(\tilde{Q}_{\mathrm{u}}\right), \\
& \tilde{Q}_{\mathrm{u}} \text { is a continuous function on } \Omega \\
& \mathcal{E}\left(u_{\mathrm{f}}, s, Q_{\mathrm{u}}\right) \leq 0 \quad \Longleftrightarrow \quad Q_{\mathrm{u}} \geq \tilde{Q}_{\mathrm{u}}\left(u_{\mathrm{f}}, s\right) .
\end{aligned}
$$

If $\left(u_{\mathrm{f}}, s\right) \in \Lambda_{3}$ then there exists a unique $Q_{\mathrm{u}}>0$ with $\left(u_{\mathrm{f}}, s\right) \in \ell_{3}\left(Q_{\mathrm{u}}\right)$. 

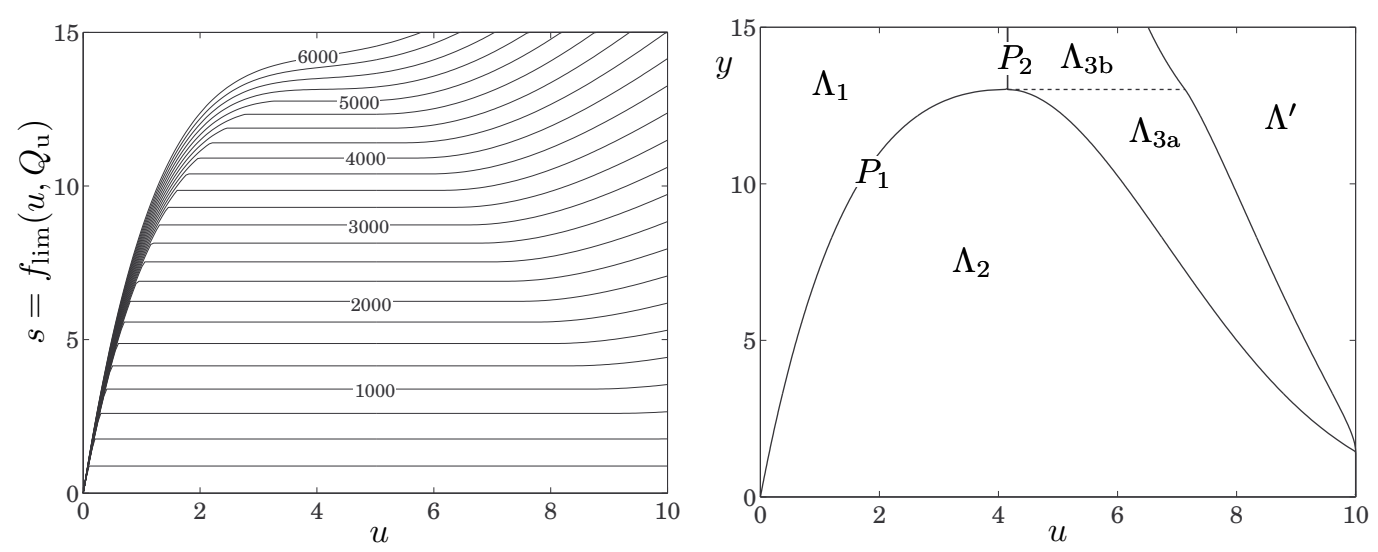

Figure 3. Operating charts for control of steady states. Left: Graphs of $f_{\lim }\left(\cdot, Q_{\mathrm{u}}\right)$ for some values of $Q_{\mathrm{u}}$. Right: The control chart with respect to steady states; $\Lambda_{3}=\Lambda_{3 \mathrm{a}} \cup \Lambda_{3 \mathrm{~b}}, \Lambda_{4}=\Lambda_{3} \cup \Lambda^{\prime}$. Theorem 3.1 says that given a feed point in this chart there is a unique graph $f_{\lim }\left(\cdot, \tilde{Q}_{\mathrm{u}}\right)$ that passes through the feed point. With the value $\tilde{Q}_{\mathrm{u}}$ the settler is critically loaded in steady state.

Choosing the particular value $Q_{\mathrm{u}}=\tilde{Q}_{\mathrm{u}} \Leftrightarrow \mathcal{E}\left(u_{\mathrm{f}}, s, \tilde{Q}_{\mathrm{u}}\right)=0$ will thus yield a critically loaded settler. It can be shown that the maximum value of the underflow concentration is

$$
\tilde{u}_{\mathrm{u}}\left(u_{\mathrm{f}}, s\right)=\frac{A s}{\tilde{Q}_{\mathrm{u}}\left(u_{\mathrm{f}}, s\right)},
$$

which is a decreasing function of $s$ for all $s>\bar{q}_{\mathrm{u}} u_{\max }$ and $u_{\mathrm{f}}<u_{\max }$. For $s \leq \bar{q}_{\mathrm{u}} u_{\max }$, $\tilde{u}_{\mathrm{u}}\left(u_{\mathrm{f}}, s\right)=u_{\max }$ holds.

Consider the last statement of Theorem 3.1. If $Q_{\mathrm{u}} \geq \overline{\bar{Q}}_{\mathrm{u}}$, then $u_{\mathrm{m}}=u_{\mathrm{M}}=u_{\mathrm{infl}}$ and the sludge blanket deteriorates. Therefore, we divide $\Lambda_{3}$ into

$$
\Lambda_{3 \mathrm{a}}=\Lambda_{3} \cap\left\{(u, y): y<f_{\mathrm{b}}\left(u_{\mathrm{infl}}\right)+\overline{\bar{q}}_{\mathrm{u}} u_{\mathrm{inf}}\right\} \quad \text { and } \quad \Lambda_{3 \mathrm{~b}}=\Lambda_{3} \backslash \Lambda_{3 \mathrm{a}},
$$

see Figure 3 (right).

The concept of optimal operation in steady state means that the concentration is zero in the clarification zone and there is a (stationary) discontinuity within the thickening zone at the depth $x=x_{\mathrm{sb}} \in(0, D)$ - the sludge blanket level (SBL). Optimal operation in steady state is one of the main control objectives discussed in [1] and it satisfies the third purpose of the settler above.

A necessary condition for optimal operation in steady state is that $\left(u_{\mathrm{f}}, s\right) \in p\left(Q_{\mathrm{u}}\right) \cup$ $\ell_{2}\left(Q_{\mathrm{u}}\right) \cup \ell_{3}\left(Q_{\mathrm{u}}\right)$ and $Q_{\mathrm{u}}<\overline{\bar{Q}}_{\mathrm{u}}$, which implies $\left(u_{\mathrm{f}}, s\right) \in P_{1} \cup \Lambda_{2} \cup \Lambda_{3 \mathrm{a}}$, see Figure 3. Sufficient conditions for obtaining this state asymptotically involve the values of the input variables and the control variable as well as the present concentration distribution. To obtain such conditions the dynamic behaviour needs to be charted. Since the continuous-sedimentation process is hardly ever in complete steady state, it is not sufficient to have control objectives only formulated in terms of steady-state solutions. Therefore, we also need a general definition of optimal operation. Let $u_{\mathrm{cl}}$ denote the restriction of the solution $u$ to the clarification zone.

DEFINITION 3.1. The settler is said to be in optimal operation at time $t$ if $Q_{\mathrm{u}}(t)<\overline{\bar{Q}}_{\mathrm{u}}$ and the solution of (1) satisfies:

$$
\text { - } u_{\mathrm{cl}}(x, t)=0 \Leftrightarrow u(x, t)=0,-H<x<0,
$$


- there exists a level $x_{\mathrm{sb}}(t) \in(0, D)$ such that

$$
u(x, t) \in \begin{cases}{\left[0, u_{\text {infl }}\right),} & 0<x<x_{\mathrm{sb}}(t) \\ {\left[u_{\text {infl }}, u_{\text {max }}\right],} & x_{\mathrm{sb}}(t)<x<D .\end{cases}
$$

Hence, we have a natural definition of the SBL for a settler in optimal operation: it is the discontinuity at the level $x=x_{\mathrm{sb}}(t)$ in the thickening zone, such that the jump in the concentration passes the characteristic concentration $u_{\text {infl }}$.

\section{Control objectives}

The three purposes of the settler in Section 2 can be written in terms of the solution of (1), namely the two output concentrations and the concentration distribution in the settler:

1. $u_{\mathrm{e}}(t)=0$

2. $u_{\mathrm{u}}(t)$ is maximized or bounded below

3. The settler is in optimal operation.

With our definition of optimal operation purpose 1 is a subset of purpose 3 . As regards steadystate situations, we know from [1] that purpose 2 is fulfilled as $Q_{\mathrm{u}}$ is minimized. Purpose 1 is, on the other hand, satisfied as $Q_{\mathrm{u}}$ is sufficiently high. The boundary case, in which purposes 1 and 2 are fulfilled, is when the settler is critically loaded in steady state, which can always be attained according to Theorem 3.1. Optimal operation is also an intermediate state, however, it is not equivalent to a critically loaded settler. The extra advantages of purpose 3 are the buffer and robustness properties of the settler.

For high loads optimal operation cannot be maintained infinitely long, as we shall see. Therefore, given a lower bound $u_{\mathrm{u}}^{\min }$ on the underflow concentration, we define the control objectives in Table I. When optimal operation cannot be maintained a second condition takes effect, and if this can only be satisfied during a finite time, a third condition takes effect. Thereby, all four objectives can always be met (with the natural interpretation $Q_{\mathrm{u}}=Q_{\mathrm{f}} \Leftrightarrow$ $Q_{\mathrm{e}}=0$ means that $u_{\mathrm{e}}=0$ ). In $\mathrm{CO} 4$, particles are allowed in the clarification zone any time, but in $\mathrm{CO} 2$ and $\mathrm{CO} 3$ only after optimal operation cannot be maintained. This limits the

Table I. Control objectives. For each control objective the first condition should be maintained as long as possible. After that, the next condition should be met as long as possible, etc.

\begin{tabular}{|l|l|l|l|}
\hline Objective & 1st condition & 2nd condition & 3rd condition \\
\hline $\mathrm{CO} 1$ & Optimal operation & $u_{\mathrm{cl}}=0$ & \\
\hline $\mathrm{CO} 2$ & Optimal operation & $u_{\mathrm{u}} \geq u_{\mathrm{u}}^{\min }$ subject to $u_{\mathrm{e}}=0$ & $u_{\mathrm{e}}=0$ \\
\hline $\mathrm{CO} 3$ & Optimal operation subject to $u_{\mathrm{u}} \geq u_{\mathrm{u}}^{\min }$ & $u_{\mathrm{u}} \geq u_{\mathrm{u}}^{\min }$ subject to $u_{\mathrm{e}}=0$ & $u_{\mathrm{e}}=0$ \\
\hline $\mathrm{CO} 4$ & $u_{\mathrm{u}}$ is maximized subject to $u_{\mathrm{e}}=0$ & & \\
\hline
\end{tabular}




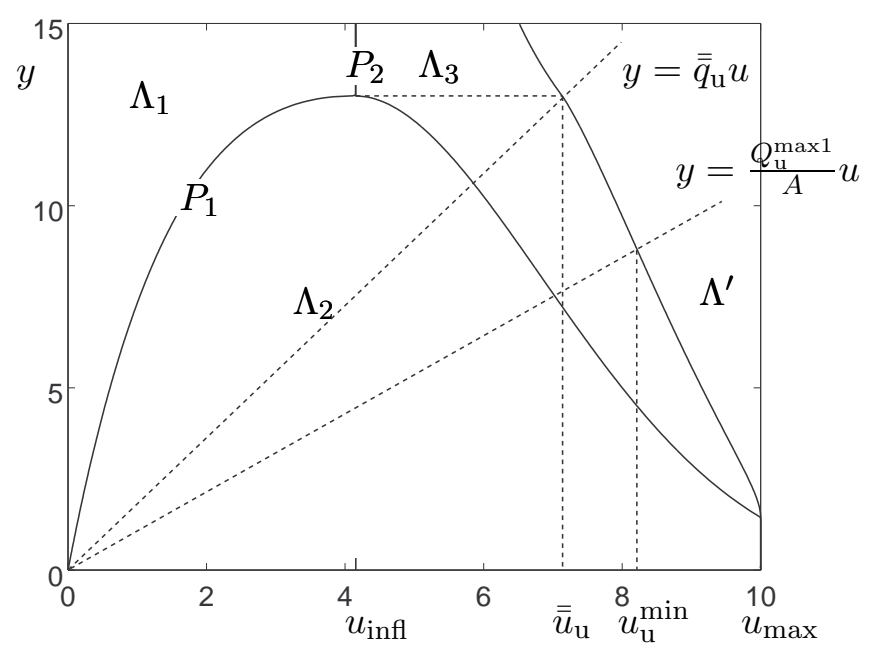

Figure 4. The characteristic concentrations of Theorem 4.1 can be obtained graphically in the operating chart for control of steady states. $\overline{\bar{u}}_{\mathrm{u}} \approx 7.13 \mathrm{~kg} / \mathrm{m}^{3}$ satisfies $f\left(u_{\mathrm{inf}}, \overline{\bar{Q}}_{\mathrm{u}}\right)=\overline{\bar{q}}_{\mathrm{u}} \overline{\bar{u}}_{\mathrm{u}} . Q_{\mathrm{u}}^{\max 1}$ can be obtained graphically in the following way. Given $u_{\mathrm{u}}^{\min } \in\left(\overline{\bar{u}}_{\mathrm{u}}, u_{\max }\right]$ determine the corresponding $y$-value on the boundary of $\Lambda_{3}$ and $\Lambda^{\prime}$. This flux value is equal to $Q_{\mathrm{u}}^{\max 1} u_{\mathrm{u}}^{\min } / A$.

mass-buffer property of the settler and increases the risk of an overflow due to disturbances. Thus, there are major disadvantages with $\mathrm{CO} 4$ in comparison to the other objectives. $\mathrm{CO} 4$ can only be 'advantageous' during transient periods in the sense that $u_{\mathrm{u}}(t)$ may be slightly higher than its maximum value in steady state, $\tilde{u}_{\mathrm{u}}$ (see Eq. (2)). Therefore, we do not consider $\mathrm{CO} 4$ in this article. Note that $\mathrm{CO} 3$ is the same as $\mathrm{CO} 2$ plus the constraint that $u_{\mathrm{u}}(t)$ is alwyas bounded below. This can be described in terms of the control variable a priori during favourable conditions, see Theorem 4.1 and Figure 4.

THEOREM 4.1. Assume that the settler is in optimal operation for $0 \leq t \leq T$.

- The underflow concentration satisfies $u_{\mathrm{u}}(t) \in\left(\overline{\bar{u}}_{\mathrm{u}}, u_{\max }\right]$ for $0 \leq t \leq T$, where $\overline{\bar{u}}_{\mathrm{u}}=$ $f\left(u_{\mathrm{infl}}, \overline{\bar{Q}}_{\mathrm{u}}\right) / \overline{\bar{q}}_{\mathrm{u}}$.

- Let $u_{\mathrm{u}}^{\min } \in\left(\overline{\bar{u}}_{\mathrm{u}}, u_{\max }\right)$ be a given desired lower bound on the underflow concentration. Assume that $Q_{\mathrm{u}}(t) \leq Q_{\mathrm{u}}^{\max 1}$, where $Q_{\mathrm{u}}^{\max 1}$ is defined ${ }^{1}$ uniquely by

$$
f\left(u_{\mathrm{M}}\left(Q_{\mathrm{u}}^{\max 1}\right), Q_{\mathrm{u}}^{\max 1}\right)=\frac{Q_{\mathrm{u}}^{\max 1}}{A} u_{\mathrm{u}}^{\min } .
$$

Then $u_{\mathrm{u}}(t) \geq u_{\mathrm{u}}^{\min }$ for $0 \leq t \leq T$ and $Q_{\mathrm{u}}^{\max 1}>\bar{Q}_{\mathrm{u}}$.

Proof. The definition of optimal operation means that $Q_{\mathrm{u}} \in\left(0, \overline{\bar{Q}}_{\mathrm{u}}\right)$ and that, for every fixed $t \in[0, T]$, the limit bottom concentration satisfies $u_{D} \equiv u(D-0, t) \in\left[u_{\text {infl }}, u_{\text {max }}\right]$. The boundary limit given by [2, Eq. (6)] implies $u^{D}(t) \equiv \lim _{\varepsilon \backslash 0} u_{D}(t+\varepsilon) \in\left[u_{\mathrm{M}}\left(Q_{\mathrm{u}}\right), u_{\max }\right]$. The underflow concentration is then given by [2, Eq. (8)];

$$
u_{\mathrm{u}}(t)=\frac{f\left(u^{D}(t)\right)}{q_{\mathrm{u}}}=u^{D}(t)+\frac{A f_{\mathrm{b}}\left(u^{D}(t)\right)}{Q_{\mathrm{u}}},
$$

\footnotetext{
${ }^{1}$ The notation $Q_{\mathrm{u}}^{\max }$ will be used, in the subsequent paper in this series, for a more general upper bound of the control variable in the connection with a regulator.
} 
which defines a continuously differentiable function $u_{\mathrm{u}}\left(u^{D}, Q_{\mathrm{u}}\right)$ for fixed $t$. We have

$$
\frac{\partial u_{\mathrm{u}}}{\partial u^{D}}=1+\frac{A f_{\mathrm{b}}^{\prime}\left(u^{D}\right)}{Q_{\mathrm{u}}}=\frac{Q_{\mathrm{u}}}{A} f^{\prime}\left(u^{D}\right) \geq 0, \quad u^{D} \in\left[u_{\mathrm{M}}\left(Q_{\mathrm{u}}\right), u_{\max }\right] .
$$

Hence, for each $Q_{\mathrm{u}} \in\left(0, \overline{\bar{Q}}_{\mathrm{u}}\right)$,

$$
\min _{u^{D} \in\left[u_{\mathrm{M}}\left(Q_{\mathrm{u}}\right), u_{\max }\right]} u_{\mathrm{u}}\left(u^{D}, Q_{\mathrm{u}}\right)=u_{\mathrm{u}}\left(u_{\mathrm{M}}\left(Q_{\mathrm{u}}\right), Q_{\mathrm{u}}\right) \stackrel{(4)}{=} u_{\mathrm{M}}\left(Q_{\mathrm{u}}\right)+\frac{A f_{\mathrm{b}}\left(u_{\mathrm{M}}\left(Q_{\mathrm{u}}\right)\right)}{Q_{\mathrm{u}}} .
$$

We investigate the latter relation between $u_{\mathrm{u}}$ and $Q_{\mathrm{u}}$. For $0<Q_{\mathrm{u}} \leq \bar{Q}_{\mathrm{u}}$ we have

$$
u_{\mathrm{u}}\left(u_{\mathrm{M}}\left(Q_{\mathrm{u}}\right), Q_{\mathrm{u}}\right)=u_{\mathrm{u}}\left(u_{\max }, Q_{\mathrm{u}}\right)=u_{\max }+\frac{A f_{\mathrm{b}}\left(u_{\max }\right)}{Q_{\mathrm{u}}}=u_{\max } .
$$

For $\bar{Q}_{\mathrm{u}}<Q_{\mathrm{u}}<\overline{\bar{Q}}_{\mathrm{u}}$ we can use the fact that $\left.\frac{d}{d Q_{\mathrm{u}}} f\left(u_{\mathrm{M}}\left(Q_{\mathrm{u}}\right), Q_{\mathrm{u}}\right)\right)=u_{\mathrm{M}}\left(Q_{\mathrm{u}}\right) / A<u_{\max } / A$, see (A2) in [1], to conclude that

$$
\begin{gathered}
\left.\left.\frac{d}{d Q_{\mathrm{u}}} u_{\mathrm{u}}\left(u_{\mathrm{M}}\left(Q_{\mathrm{u}}\right), Q_{\mathrm{u}}\right)=-\frac{A}{Q_{\mathrm{u}}^{2}} f\left(u_{\mathrm{M}}\left(Q_{\mathrm{u}}\right), Q_{\mathrm{u}}\right)\right)+\frac{A}{Q_{\mathrm{u}}} \frac{d}{d Q_{\mathrm{u}}} f\left(u_{\mathrm{M}}\left(Q_{\mathrm{u}}\right), Q_{\mathrm{u}}\right)\right)= \\
\left.=\frac{A}{Q_{\mathrm{u}}^{2}}\left(-f\left(u_{\mathrm{M}}\left(Q_{\mathrm{u}}\right), Q_{\mathrm{u}}\right)\right)+\frac{Q_{\mathrm{u}}}{A} u_{\mathrm{M}}\left(Q_{\mathrm{u}}\right)\right)=-\frac{A f_{\mathrm{b}}\left(u_{\mathrm{M}}\left(Q_{\mathrm{u}}\right)\right)}{Q_{\mathrm{u}}^{2}}<0 .
\end{gathered}
$$

Thus, the continuous function $u_{\mathrm{u}}\left(u_{\mathrm{M}}\left(Q_{\mathrm{u}}\right), Q_{\mathrm{u}}\right)$ of $Q_{\mathrm{u}}$ is decreasing for $\bar{Q}_{\mathrm{u}} \leq Q_{\mathrm{u}}<\overline{\bar{Q}}_{\mathrm{u}}$ taking all values from $u_{\max }$ down to

$$
u_{\mathrm{u}}\left(u_{\mathrm{M}}\left(\overline{\bar{Q}}_{\mathrm{u}}\right), \overline{\bar{Q}}_{\mathrm{u}}\right)=u_{\mathrm{u}}\left(u_{\mathrm{inf}}, \overline{\bar{Q}}_{\mathrm{u}}\right)=u_{\mathrm{infl}}+\frac{A f_{\mathrm{b}}\left(u_{\mathrm{inf}}\right)}{\overline{\bar{Q}}_{\mathrm{u}}}=\frac{f\left(u_{\mathrm{inf}}, \overline{\bar{Q}}_{\mathrm{u}}\right)}{\overline{\bar{q}}_{\mathrm{u}}}=\overline{\bar{u}}_{\mathrm{u}} .
$$

Hence, for given $u_{\mathrm{u}}^{\min } \in\left(\overline{\bar{u}}_{\mathrm{u}}, u_{\max }\right)$ there exists a unique value $Q_{\mathrm{u}}^{\max 1}>\bar{Q}_{\mathrm{u}}$ such

$$
u_{\mathrm{u}}^{\min }=u_{\mathrm{u}}\left(u_{\mathrm{M}}\left(Q_{\mathrm{u}}^{\max 1}\right), Q_{\mathrm{u}}^{\max 1}\right)=u_{\mathrm{M}}\left(Q_{\mathrm{u}}^{\max 1}\right)+\frac{A f_{\mathrm{b}}\left(u_{\mathrm{M}}\left(Q_{\mathrm{u}}^{\max 1}\right)\right)}{Q_{\mathrm{u}}^{\max 1}},
$$

which after multiplying by $Q_{\mathrm{u}}^{\max 1} / A$ finishes the proof.

\section{Control strategies}

Assume that the feed point $\left(u_{\mathrm{f}}(t), s(t)\right)$ moves around, continuously and/or discontinuously, in the operating chart. To fulfil any control objective, control strategies need to be specified, which means that $Q_{\mathrm{u}}$ is defined as a function of the feed point and time. By a control action we mean a relation between $Q_{\mathrm{u}}$ and $\left(u_{\mathrm{f}}, s\right)$ at a fixed time point. In order to propose control strategies we define the following subsets, or lines, in the operating chart:

$$
\begin{aligned}
& L_{1}=\bigcup_{i=1}^{3} \ell_{i} \cup p \cup\left\{(u, y): y=q_{\mathrm{u}} u, \frac{f\left(u_{\mathrm{M}}\right)}{q_{\mathrm{u}}}<u \leq u_{\max }\right\}, \\
& L_{2}=\left\{(u, y): y=f_{\lim }(u)\right\}=\ell_{1} \cup p \cup \ell_{2} \cup \ell_{4},
\end{aligned}
$$




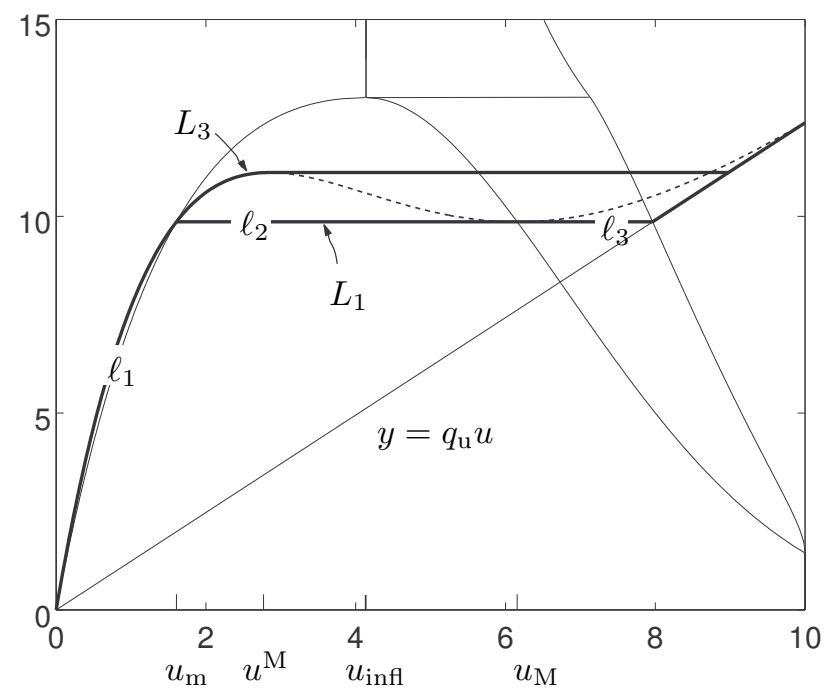

Figure 5. The sets $L_{1}$ and $L_{3}$. Note that the feed point lies on the line $y=q_{\mathrm{u}} u$ if and only if $Q_{\mathrm{e}}=0 \Leftrightarrow Q_{\mathrm{u}}=Q_{\mathrm{f}}$.

$$
L_{3}=\left\{(u, y): y=f_{3}(u)\right\} \quad \text { where } \quad f_{3}(u)= \begin{cases}f(u), & 0 \leq u \leq u^{\mathrm{M}} \\ f\left(u^{\mathrm{M}}\right), & u^{\mathrm{M}}<u \leq \frac{f\left(u^{\mathrm{M}}\right)}{q_{\mathrm{u}}} \\ q_{\mathrm{u}} u, & \frac{f\left(u^{\mathrm{M}}\right)}{q_{\mathrm{u}}}<u \leq u_{\max }\end{cases}
$$

Note that these sets depend on $Q_{\mathrm{u}}$, for example, $\left(u_{\mathrm{f}}, s\right) \in L_{2}\left(Q_{\mathrm{u}}\right)$ means that the settler is critically loaded in the corresponding steady state. $L_{1}$ and $L_{3}$ are shown in Figure 5. Some control strategies are the following:

DCL1.: Direct control with respect to $L_{1}$, i.e., define $Q_{\mathrm{u}}(t)$ such that $\left(u_{\mathrm{f}}(t), s(t)\right) \in L_{1}\left(Q_{\mathrm{u}}(t)\right)$.

DCL2 and DCL3 are defined analogously.

PCC: Piecewise constant control of $Q_{\mathrm{u}}(t)$ where decisions are made depending both on the location of the feed point in the operating chart and the actual concentration distribution in the settler, especially the SBL.

Thus, for the step inputs in this paper, DC means that a single step control action is performed at $t=0$. Omitting the initials DC means that the control action is performed at a later time point. Strategy DCL2 is motivated by the results on the control of steady states in [1] and can always be accomplished according to Theorem 3.1. With a small adjustment of the proof of that theorem it is easy to establish that strategies DCL1 and DCL3 can always be accomplished with a unique value of $Q_{\mathrm{u}}$ for each given feed point. It is convenient to use the notation $Q_{\mathrm{u}}=L_{1}^{-1}\left(u_{\mathrm{f}}, s\right) \Leftrightarrow\left(u_{\mathrm{f}}, s\right) \in L_{1}\left(Q_{\mathrm{u}}\right)$ etc. Strategy DCL1 is equal to DCL2 for feed points in $P \cup \Lambda_{2}$. For $\left(u_{\mathrm{f}}, s\right) \in \Lambda_{3} \subset \Lambda_{4}$ there is a choice between making a control action with respect to a critically loaded settler, $Q_{\mathrm{u}}=\ell_{4}^{-1}\left(u_{\mathrm{f}}, s\right)$, which is DCL2, and setting the slightly higher value $Q_{\mathrm{u}}=\ell_{3}^{-1}\left(u_{\mathrm{f}}, s\right)$, which is DCL1 and aims at keeping optimal operation as long as possible. If $\left(u_{\mathrm{f}}, s\right) \in \Lambda^{\prime}$ there are similarly two alternatives. Optimal operation can, however, only be maintained during a finite time in the corresponding steady state, as we shall see. 
In Section 6 we show that DCL1 is better than DCL2 with respect to CO1 for the control of step responses. An advantage of DCL1 and DCL2 over PCC is that these ignore the present concentration distribution in the settler. A drawback of DCL2 (and similarly for DCL1) is that $Q_{\mathrm{u}}(t)$ is only implicitly defined by the non-linear equation $\mathcal{E}\left(u_{\mathrm{f}}, s, Q_{\mathrm{u}}\right)=0$, which generally has to be solved numerically for $Q_{\mathrm{u}}=\tilde{Q}_{\mathrm{u}}$. In practise it may also take some time to realize a new flow value. Therefore, these strategies cannot be realized exactly. The simplicity of the strategy PCC - adjust the control parameter only at certain time points and keep it constant in between - is obvious and in many waste-water treatment plants the only possibility in practice. In Section 7 the strategy PCC will be specified further concerning the control of step responses. As we shall see, this strategy is sufficient for fulfilling $\mathrm{CO} 1$ or $\mathrm{CO} 2$ and the strategies DCL2 and DCL1 may actually be disadvantageous. The use of strategy DCL3 is also demonstrated in Section 7.

\section{Direct control of step inputs}

\subsection{OPERATING CHART FOR DIRECT CONTROL OF STEP INPUTS}

Assume that the settler is in optimal operation and steady state initially, that there is a step change at $t=0$ in the feed variables, and that these are constant thereafter. In this section we present the solution to a single step control action which is performed directly. Since we aim at a stationary settler in optimal operation only the control actions DCL1 and DCL2 will be considered in this section. The advantage of DCL1 over DCL2 will be emphasized in Sections 6.3, 6.5 and 6.7. It turns out that the qualitatively different cases depend on both the underloaded region, denoted by $\mathcal{U}=\mathcal{U}_{1} \cup \ell_{3} \cup \mathcal{U}_{2}$, the overloaded region, $\mathcal{O}=\mathcal{O}_{1} \cup \ell_{5} \cup$ $\mathcal{O}_{2} \cup \mathcal{O}_{3}$, and on the control chart in Figure 3 (right). In the latter the set $\Lambda^{\prime}$ now have to be be divided further depending on whether $s \lessgtr f\left(u^{\mathrm{M}}\right)$ after the control action DCL1. Since the value of the control variable can be written in terms of the feed variables, $Q_{\mathrm{u}}=Q_{\mathrm{f}}=A s / u_{\mathrm{f}}$, the set $\Lambda^{\prime}$ can be divided beforehand:

$$
\begin{aligned}
& \left.\Lambda_{\mathrm{a}}^{\prime}=\left\{(u, y) \in \Lambda^{\prime}: y \leq f\left(u^{\mathrm{M}}(A y / u) ; A y / u\right)\right)\right\}, \\
& \Lambda_{\mathrm{b}}^{\prime}=\Lambda^{\prime} \backslash \Lambda_{\mathrm{a}}^{\prime},
\end{aligned}
$$

see Figure 6, where these sets are shown (above the line $y=q_{\mathrm{u}} u$ ). This means that the intersection of the line $y=q_{\mathrm{u}} u$ and the dividing curve between $\Lambda_{\mathrm{a}}^{\prime}$ and $\Lambda_{\mathrm{b}}^{\prime}$ occurs at the height of the local maximum of $f$, i.e., $f\left(u^{\mathrm{M}}\right)$.

As for the construction of solutions, we leave out many details as well as some auxiliary figures of flux functions. The principles have been demonstrated in the previous paper [2]. The index 0 denotes the value of a variable at $t=0-$. Recall that the time dependent variables are defined to be continuous from the right, for example, $u_{\mathrm{f} 0}=u_{\mathrm{f}}(0-) \neq u_{\mathrm{f}}(0+)=u_{\mathrm{f}}(0)$. Variables written without the zero index correspond to constant values in the new steady state, which may arise after a finite or infinite time. Since the control parameter makes a jump at $t=0$ from $Q_{\mathrm{u} 0}$ to $Q_{\mathrm{u}}$, we need to differentiate between the initial flux $f_{0}(\cdot) \equiv f\left(\cdot ; Q_{\mathrm{u} 0}\right)$ and the new one $f(\cdot) \equiv f\left(\cdot ; Q_{\mathrm{u}}\right)$. For variables that vary continuously during the transient period, or some part of it, the time dependence is written out, for example, $m(t)$ or $u_{\mathrm{e}}(t)$. Their values in the new steady state are then written out explicitly, for example, $m\left(t_{5}\right)$ is the constant mass for $t \geq t_{5}$, and we write $u_{\mathrm{e} \infty}$ for an asymptotic value. 


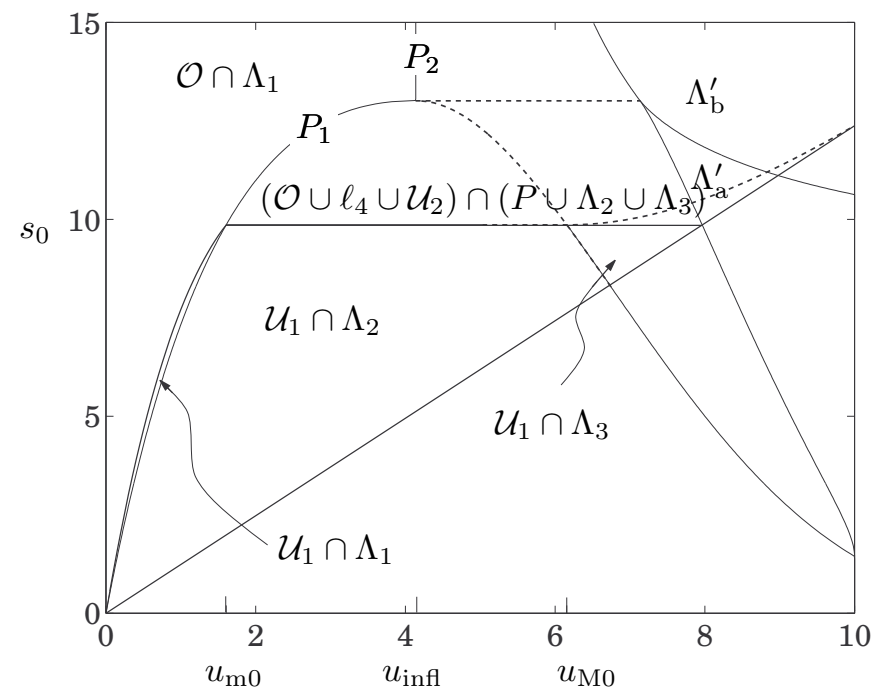

Figure 6. The operating chart for direct control of step inputs shows the regions (within the solid lines) of the qualitatively different solutions. The sets refer to the initial value $Q_{\mathrm{u} 0}$, i.e., $\mathcal{O} \equiv \mathcal{O}\left(Q_{\mathrm{u} 0}\right)$ etc. Recall that $P_{1} \cup P_{2}=P$.

Initial conditions: The settler is initially in optimal operation at steady state, i.e., the feed point $\left(u_{\mathrm{f} 0}, s_{0}\right) \in p \cup \ell_{2} \cup \ell_{3}$, there is zero concentration in the clarification zone and a sludge blanket in the thickening zone at the depth $x_{\mathrm{sb} 0}$ with the concentration $u_{\mathrm{m} 0}$ above and $u_{\mathrm{M} 0}$ below it. The total mass in the settler is thus initially

$$
m_{0}=A\left(x_{\mathrm{sb} 0} u_{\mathrm{m} 0}+\left(D-x_{\mathrm{sb} 0}\right) u_{\mathrm{M} 0}\right) .
$$

Numerical data and simulations: The following numerical data are used throughout the paper:

$$
\begin{array}{ll}
H=1 \mathrm{~m}, & u_{\max }=10 \mathrm{~kg} / \mathrm{m}^{3}, \\
D=4 \mathrm{~m}, & u_{\text {infl }}=4.15 \mathrm{~kg} / \mathrm{m}^{3}, \\
A=\pi(30 \mathrm{~m})^{2}=2827 \mathrm{~m}^{2}, & x_{\mathrm{sb} 0}=2 \mathrm{~m} \text { (unless otherwise stated). }
\end{array}
$$

Note that the initial mass depends on the values of $u_{\mathrm{m} 0}$ and $u_{\mathrm{M} 0}$, which depend on $Q_{\mathrm{u} 0}=Q_{\mathrm{u}}$. The latter variable is, for clarity, set to different values in the different cases below, which means that the initial mass is different, too. We only show the interesting cases when $Q_{\mathrm{u}}<$ $\overline{\bar{Q}}_{\mathrm{u}}=5161 \mathrm{~m}^{3} / \mathrm{h}$, cf. Figure 3 (left). The batch settling flux $f_{\mathrm{b}}(u)$ used is shown in Figure 1 (right). The three-dimensional graphs are obtained by the numerical method described in [11]. Unless otherwise stated, the initial data are

$$
\begin{array}{ll}
Q_{\mathrm{u} 0}=3500 \mathrm{~m}^{3} / \mathrm{h}, & s_{0}=9.86 \mathrm{~kg} /\left(\mathrm{m}^{2} \mathrm{~h}\right), \\
u_{\mathrm{m} 0}=1.61 \mathrm{~kg} / \mathrm{m}^{3}, & u_{\mathrm{M} 0}=6.16 \mathrm{~kg} / \mathrm{m}^{3}, \\
u_{\mathrm{u} 0}=7.96 \mathrm{~kg} / \mathrm{m}^{3}, & u_{\mathrm{m} 0}<u_{\mathrm{f} 0} \leq u_{\mathrm{M} 0},
\end{array}
$$

cf. Figure 7. In the cases below we thus assume that $s_{0}>\bar{q}_{\mathrm{u}} u_{\max }=1.45 \mathrm{~kg} /\left(\mathrm{m}^{2} \mathrm{~h}\right)$. Otherwise, $u_{\mathrm{M} 0}=u_{\mathrm{u} 0}=u_{\max }$ and some of the inequalities become equalities. In all cases in this section the effluent concentration is zero. We do not show simulation graphs of this or the evolution of the mass. 


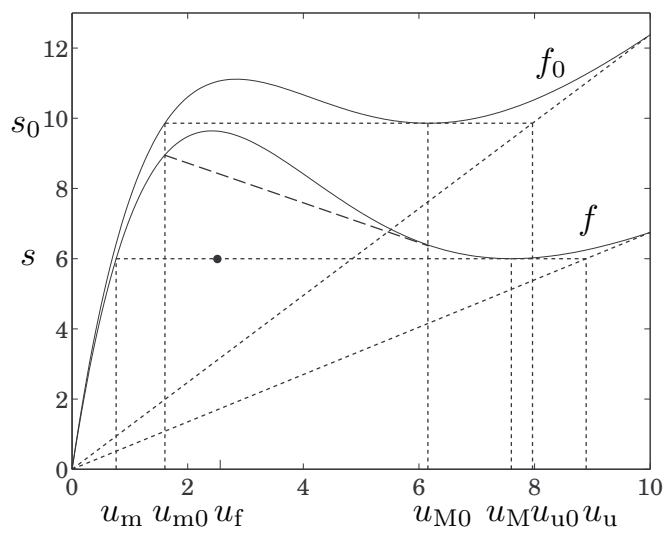

Figure 7. $\left.\left(u_{\mathrm{f}}, s\right)=2 \cdot 5,6 \cdot 0\right) \in \mathcal{U}_{1}\left(Q_{\mathrm{u} 0}\right) \cap \Lambda_{2}$. The graphs of the initial flux $f_{0}(\cdot) \equiv f\left(\cdot ; Q_{\mathrm{u} 0}\right)$ and the new one $f(\cdot) \equiv f\left(\cdot ; Q_{\mathrm{u}}\right)$.

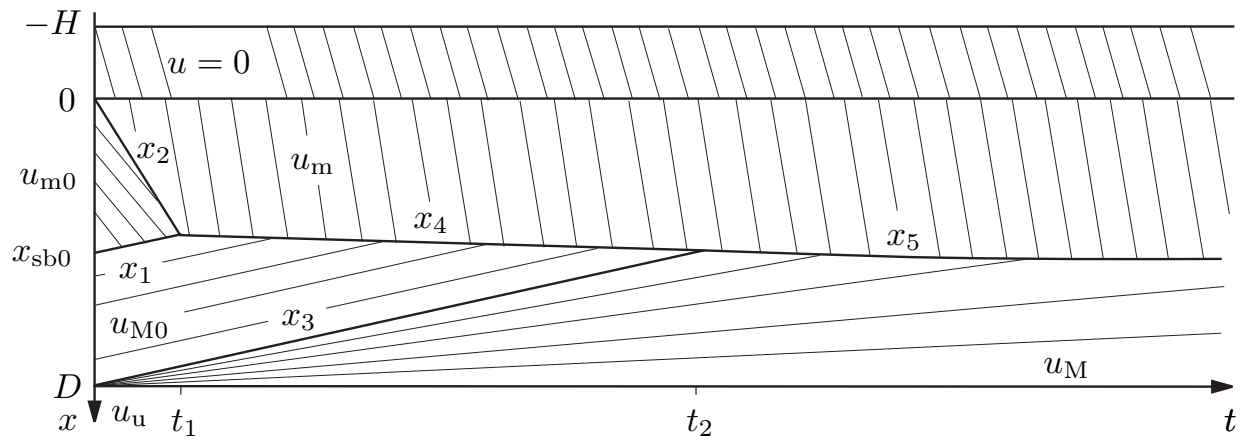

Figure 8. Solution of a response to DCL1 as $\left(u_{\mathrm{f}}, s\right) \in \mathcal{U}_{1}\left(Q_{\mathrm{u} 0}\right) \cap \ell_{2}\left(Q_{\mathrm{u}}\right)$.

\section{2. $\left(u_{\mathrm{f}}, s\right) \in \mathcal{U}_{1}\left(Q_{\mathrm{u} 0}\right) \cap\left(P \cup \Lambda_{2}\right)$}

Suppose the new feed point is $\left(u_{\mathrm{f}}, s\right)=(2.5,6.0) \in \mathcal{U}_{1}\left(Q_{\mathrm{u} 0}\right) \cap \Lambda_{2}$, see Figure 7. According to DCL1 $=$ DCL2 we let $Q_{\mathrm{u}}=\tilde{Q}_{\mathrm{u}} \approx 1908$, which implies $\left(u_{\mathrm{f}}, s\right) \in \ell_{2}\left(Q_{\mathrm{u}}\right)$ As we shall see, the settler will be kept in optimal operation. The graphs of the initial and the new flux functions for the thickening zone are shown in Figure 7 together with some concentrations that appear in the solution. According to Condition $\Gamma$ the boundary values are $u^{-}(t)=0, u^{+}(t)=u_{\mathrm{m}}$ and $u^{D}(t)=u_{\mathrm{M}}$ for $t \geq 0$. The solution is shown in Figure 8. (The slopes of the characteristics with the concentration $u_{\mathrm{m}}$ between $x_{1}$ and $x_{2}$ may be zero or negative if $Q_{\mathrm{u} 0}$ is high and $Q_{\mathrm{u}}$ low, i.e., $u_{\mathrm{m} 0}$ lies at or to the right of $u^{\mathrm{M}}$.) The underflow concentration changes immediately from the initial value $u_{\mathrm{u} 0}=7.96$ to the new value $u_{\mathrm{u}}=8.89$. There is an expansion wave at the bottom below the line of continuity $x_{3}=f^{\prime}\left(u_{\mathrm{M} 0}\right) t+D$, along which the concentration is $u_{\mathrm{M} 0}$. The line $x_{1}$ is a contact discontinuity with the speed

$$
x_{1}^{\prime}(t)=S_{f}\left(u_{\mathrm{m} 0}, u_{\mathrm{M} 0}\right)=S_{f}\left(u_{\mathrm{m} 0}, u_{\mathrm{m} 0}{ }^{*}\right)=f^{\prime}\left(u_{\mathrm{M} 0}\right),
$$

since $u_{\mathrm{m}}\left(Q_{\mathrm{u}}\right)^{*}=u_{\mathrm{M}}\left(Q_{\mathrm{u}}\right)$ for all values of $Q_{\mathrm{u}}$ ( [2, Lemma 2.2]), see the long-dashed line in Figure 7. Hence, $x_{1}$ and $x_{3}$ are parallel straight lines. The discontinuities satisfy

$$
x_{1}(t)=f^{\prime}\left(u_{\mathrm{M} 0}\right) t+x_{\mathrm{sb} 0}, \quad 0<t<t_{1},
$$




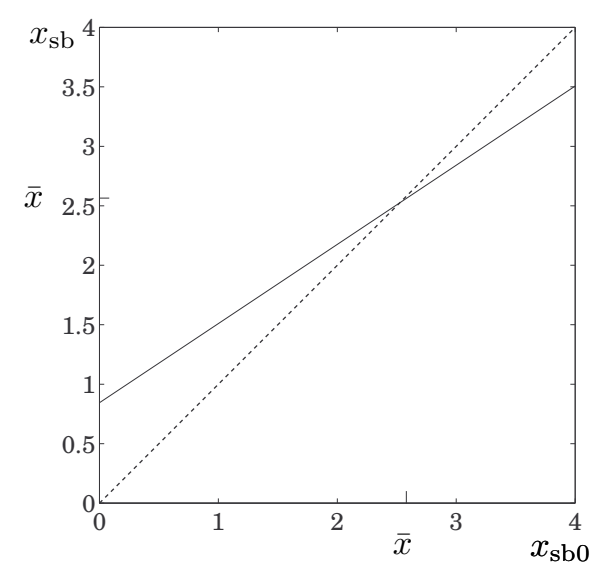

Figure 9. The solid line shows the relation (6); $x_{\mathrm{sb}}=0.67 x_{\mathrm{sb} 0}+0.84 \mathrm{~m}$. For example, $x_{\mathrm{sb} 0}=2 \mathrm{~m}$ gives $x_{\mathrm{sb}}=2.18 \mathrm{~m}$, cf. Figure 10. The fixed point under the control action is $\bar{x}=2.53 \mathrm{~m}$.

$$
\begin{array}{ll}
x_{2}(t)=S_{f}\left(u_{\mathrm{m} 0}, u_{\mathrm{m}}\right) t, & 0<t<t_{1}, \\
x_{4}(t)=S_{f}\left(u_{\mathrm{m}}, u_{\mathrm{M} 0}\right) t+x_{1}\left(t_{1}\right), & t_{1}<t<t_{2},
\end{array}
$$

where

$$
t_{1}=\frac{x_{\mathrm{sb} 0}}{S_{f}\left(u_{\mathrm{m} 0}, u_{\mathrm{m}}\right)-f^{\prime}\left(u_{\mathrm{M} 0}\right)}, \quad t_{2}=\frac{D-x_{1}\left(t_{1}\right)}{S_{f}\left(u_{\mathrm{m}}, u_{\mathrm{M} 0}\right)-f^{\prime}\left(u_{\mathrm{M} 0}\right)} .
$$

The example data we use here give $t_{1} \approx 29 \mathrm{~min}$ and $t_{2} \approx 3.6 \mathrm{~h}$. There is an expansion wave at the bottom and $x_{5}$ approaches the final SBL $x_{\mathrm{sb}}$ asymptotically, since the concentration below the SBL approaches $u_{\mathrm{M}}$ asymptotically.

Because of the monotonicity property of $\tilde{u}_{\mathrm{u}}\left(u_{\mathrm{f}}, s\right)$, defined by (2), the new underflow concentration satisfies

$$
u_{\mathrm{u}}= \begin{cases}\tilde{u}_{\mathrm{u}}\left(u_{\mathrm{f}}, s\right)>\tilde{u}_{\mathrm{u}}\left(u_{\mathrm{f} 0}, s_{0}\right)=u_{\mathrm{u} 0}, & s>\bar{q}_{\mathrm{u}} u_{\max } \\ u_{\mathrm{u} 0}=u_{\max } & s \leq \bar{q}_{\mathrm{u}} u_{\max }\end{cases}
$$

The mass in the settler is unchanged. This is because of the immediate change to the new constant underflow concentration by Condition $\Gamma$. The outgoing flux $=Q_{\mathrm{u}} u_{\mathrm{u}} / A=f\left(u_{\mathrm{M}}\right)=$ $s=$ incoming flux. Equating the expression for the mass in the settler at $t=0$, (5), and its analogue as $t \rightarrow \infty$, we get the following linear relationship between the new location of the SBL and the initial one (see Figure 9):

$$
x_{\mathrm{sb}}=\frac{x_{\mathrm{sb} 0}\left(u_{\mathrm{M} 0}-u_{\mathrm{m} 0}\right)+D\left(u_{\mathrm{M}}-u_{\mathrm{M} 0}\right)}{u_{\mathrm{M}}-u_{\mathrm{m}}} .
$$

The properties

$$
\begin{aligned}
& x_{\mathrm{sb}} \rightarrow D \frac{u_{\mathrm{M}}-u_{\mathrm{M} 0}}{u_{\mathrm{M}}-u_{\mathrm{m}}}>0 \quad \text { as } x_{\mathrm{sb} 0} \rightarrow 0, \\
& x_{\mathrm{sb}} \rightarrow D \frac{u_{\mathrm{M}}-u_{\mathrm{m} 0}}{u_{\mathrm{M}}-u_{\mathrm{m}}}<D \quad \text { as } x_{\mathrm{sb} 0} \rightarrow D,
\end{aligned}
$$




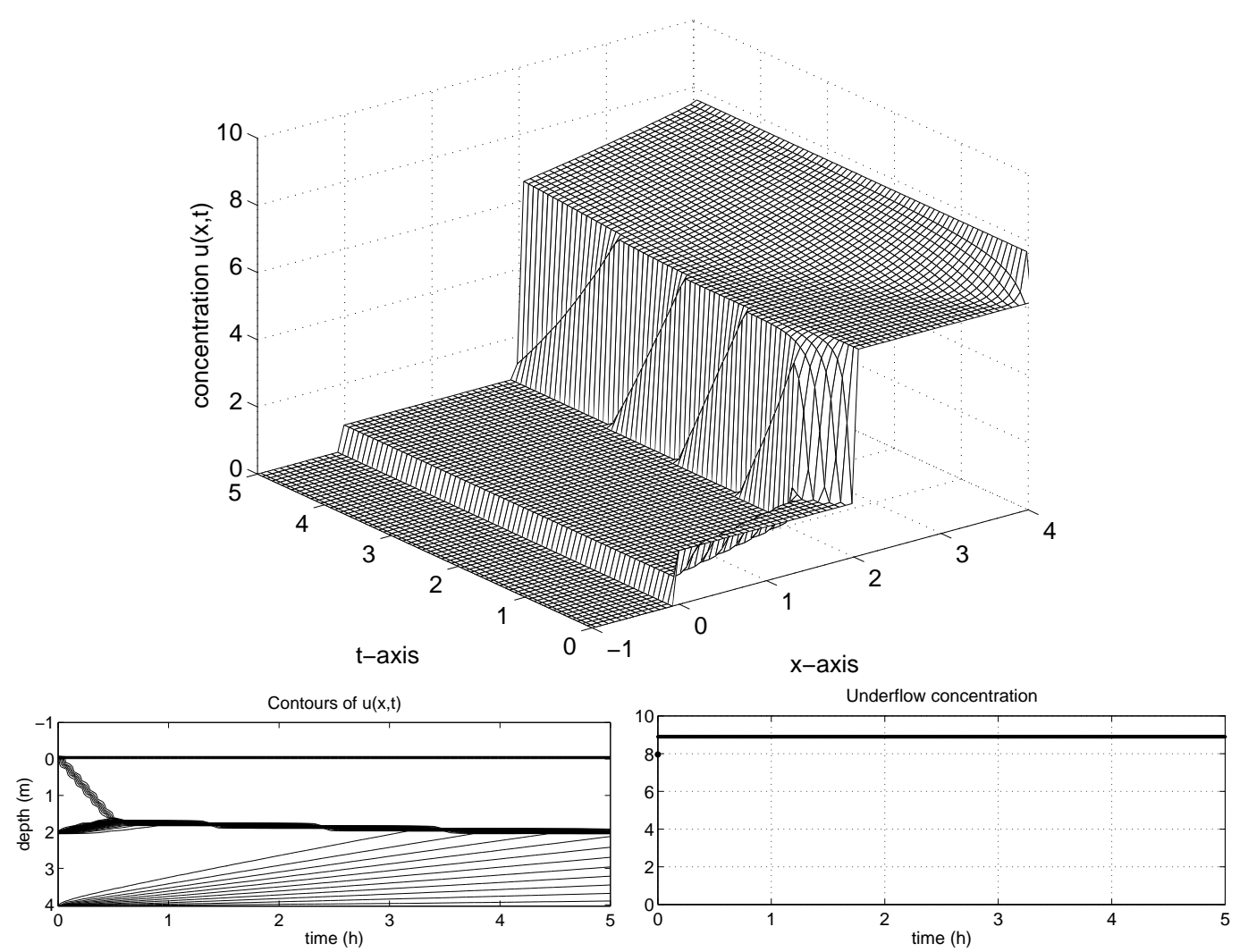

Figure 10. Numerical simulation of a response to DCL1 as $\left(u_{\mathrm{f}}, s\right)=(2.5,6.0) \in \mathcal{U}_{1}\left(Q_{\mathrm{u} 0}\right) \cap \ell_{2}\left(Q_{\mathrm{u}}=1908\right)$. Note the jump in the underflow concentration at $t=0$.

imply, firstly, that there is a unique level, a fixed point of (6),

$$
\bar{x} \equiv \frac{D}{1+\frac{u_{\mathrm{m} 0}-u_{\mathrm{m}}}{u_{\mathrm{M}}-u_{\mathrm{M} 0}}},
$$

which satisfies $x_{\mathrm{sb} 0}=\bar{x}=x_{\mathrm{sb}}$ and, secondly, that the control action has a stabilizing effect on the $S B L$ in the sense that $x_{\mathrm{sb}}$ lies closer to $\bar{x}$ than $x_{\mathrm{sb} 0}$ does; cf. Figure 9. If $s_{0} \leq \bar{q}_{\mathrm{u}} u_{\mathrm{max}}$, then $x_{\mathrm{sb}}=0$. Compare the numerical values in the text above with the numerical simulation in Figure 10.

\section{3. $\left(u_{\mathrm{f}}, s\right) \in \mathcal{U}_{1}\left(Q_{\mathrm{u} 0}\right) \cap \Lambda_{3}$}

Note that the solution in Figure 8 does not depend on the new value of the feed concentration $u_{\mathrm{f}}$. Following the control strategy DCL1 we can find a value $Q_{\mathrm{u}}<Q_{\mathrm{u} 0}$ such that $\left(u_{\mathrm{f}}, s\right) \in$ $\ell_{3}\left(Q_{\mathrm{u}}\right)$. Then the solution is qualitatively the same as in the previous case $\mathcal{U}_{1} \cap \Lambda_{2}$, however, with $f$ closer to $f_{0}$, see Figure 11 (left) and a simulation in Figure 12.

As a comparison we show in Figure 13 the solution when the slightly lower value $Q_{\mathrm{u}}=$ $\tilde{Q}_{\mathrm{u}}=3226$ is chosen according to DCL2, which implies $\left(u_{\mathrm{f}}, s\right)=(7.5,9.5) \in \mathcal{U}_{1}\left(Q_{\mathrm{u} 0}\right) \cap$ $\ell_{4}\left(\tilde{Q}_{\mathrm{u}}\right)$, see Figure 11 (right). There will not be any sludge blanket in the new steady state, which arises after a finite but long time. The solution will initially be as in Figure 8 with the concentration $u_{\mathrm{m}}$ replaced by $u_{1} \in\left(u_{\mathrm{m}}, u_{\mathrm{m} 0}\right)$, satisfying $s=f\left(u_{1}\right)$. Note that $s$ is 

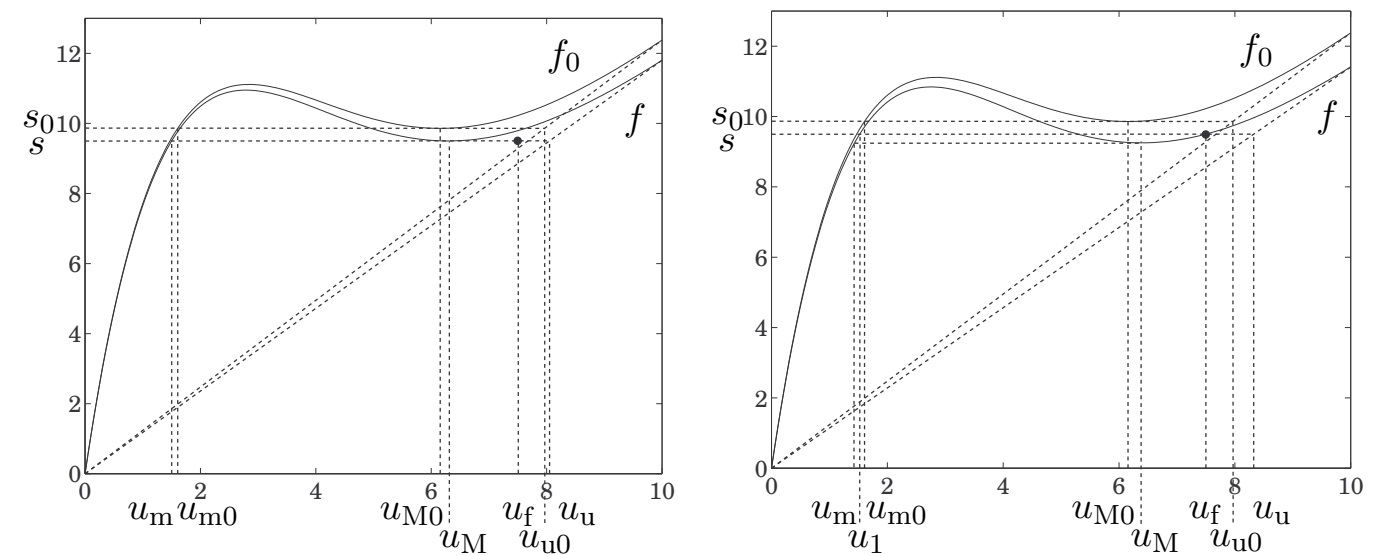

Figure 11. $\left(u_{\mathrm{f}}, s\right)=(7.5,9.5) \in \mathcal{U}_{1}\left(Q_{\mathrm{u} 0}\right) \cap \Lambda_{3}$. DCL1: $Q_{\mathrm{u}}=\ell_{3}^{-1}\left(u_{\mathrm{f}}, s\right)=3337$ (left). DCL2: $Q_{\mathrm{u}}=\ell_{4}^{-1}\left(u_{\mathrm{f}}, s\right)=3226$ (right).
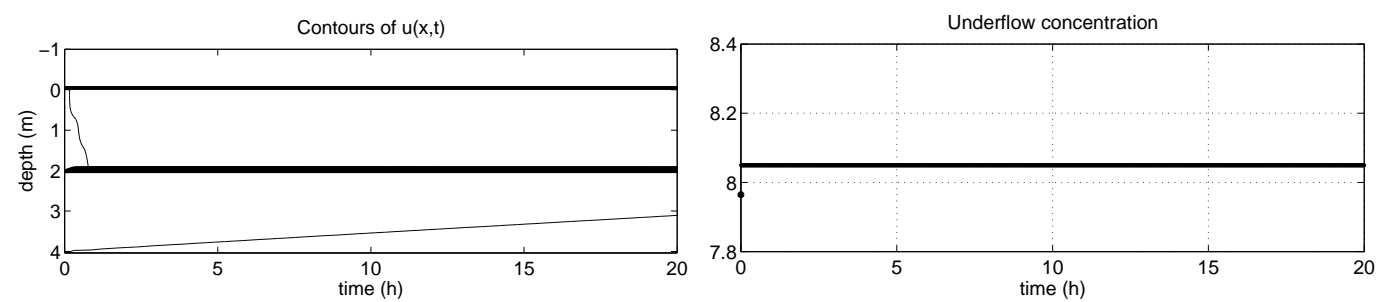

Figure 12. Numerical simulation of a response to DCL1; $\left(u_{\mathrm{f}}, s\right)=(7.5,9.5) \in \mathcal{U}_{1}\left(Q_{\mathrm{u} 0}\right) \cap \ell_{3}\left(Q_{\mathrm{u}}=3337\right)$. The settler is kept in optimal operation.

now slightly greater than $f\left(u_{\mathrm{m}}\right)=f\left(u_{\mathrm{M}}\right)$. There is a small expansion wave emanating from the bottom. Its slowest rising discontinuity carries the concentration $u_{1}^{*} \in\left(u_{\mathrm{M} 0}, u_{\mathrm{M}}\right)$. After this has met the rising sludge blanket (cf. the discontinuity $x_{5}$ in Figure 8), the speed of the sludge blanket stays at the constant and slightly negative value $x_{5}^{\prime}(t)=S_{f}\left(u_{1}, u_{1}^{*}\right)=f^{\prime}\left(u_{1}^{*}\right)$. Hence, it rises slowly until it reaches the feed level. After that time point the new boundary concentration just below the feed level is $u_{\mathrm{f}}\left(>u_{\mathrm{M}}\right)$ and this concentration is slowly spread all over the thickening zone. At this time point the underflow concentration makes a step increase from $f\left(u_{\mathrm{M}}\right) / q_{\mathrm{u}}$ to $s / q_{\mathrm{u}}$ and the new steady state begins.

\section{4. $\left(u_{\mathrm{f}}, s\right) \in\left(\ell_{1}\left(Q_{\mathrm{u} 0}\right) \cup \mathcal{U}_{1}\left(Q_{\mathrm{u} 0}\right)\right) \cap \Lambda_{1}$}

The set is represented by a narrow strip in the control chart, see Figure 6. Choosing $Q_{\mathrm{u}}=\tilde{Q}_{\mathrm{u}}$ according to DCL1 = DCL2 we obtain a solution that initially (before $t_{2}$ ) looks like the one shown in Figure 8 with the concentration $u_{\mathrm{m}}$ replaced by $u_{\mathrm{f}}$. Note that $s=f\left(u_{\mathrm{f}}\right)$ is now less than $f\left(u_{\mathrm{M} 1}\right)$, were $u_{\mathrm{M} 1}$ is the new bottom concentration at $t=0+$, see Figure 14 . This implies that the discontinuity $x_{5}$, the SBL, has positive speed varying from $S_{f}\left(u_{\mathrm{f}}, u_{\mathrm{M} 0}\right.$ ) (during $t_{1}<$ $\left.t \leq t_{2}\right)$ to the slightly lower value $S_{f}\left(u_{\mathrm{f}}, u_{\mathrm{M} 1}\right)$ as it reaches the bottom. At this time point the underflow concentration makes a step decrease from $f\left(u_{\mathrm{M} 1}\right) / q_{\mathrm{u}}$ to $f\left(u_{\mathrm{f}}\right) / q_{\mathrm{u}}=s / q_{\mathrm{u}}$. A numerical simulation in the case $\left(u_{\mathrm{f}}, s\right)=(1,7.5)$ and $\tilde{Q}_{\mathrm{u}}=2907$ is shown in Figure 15 . 


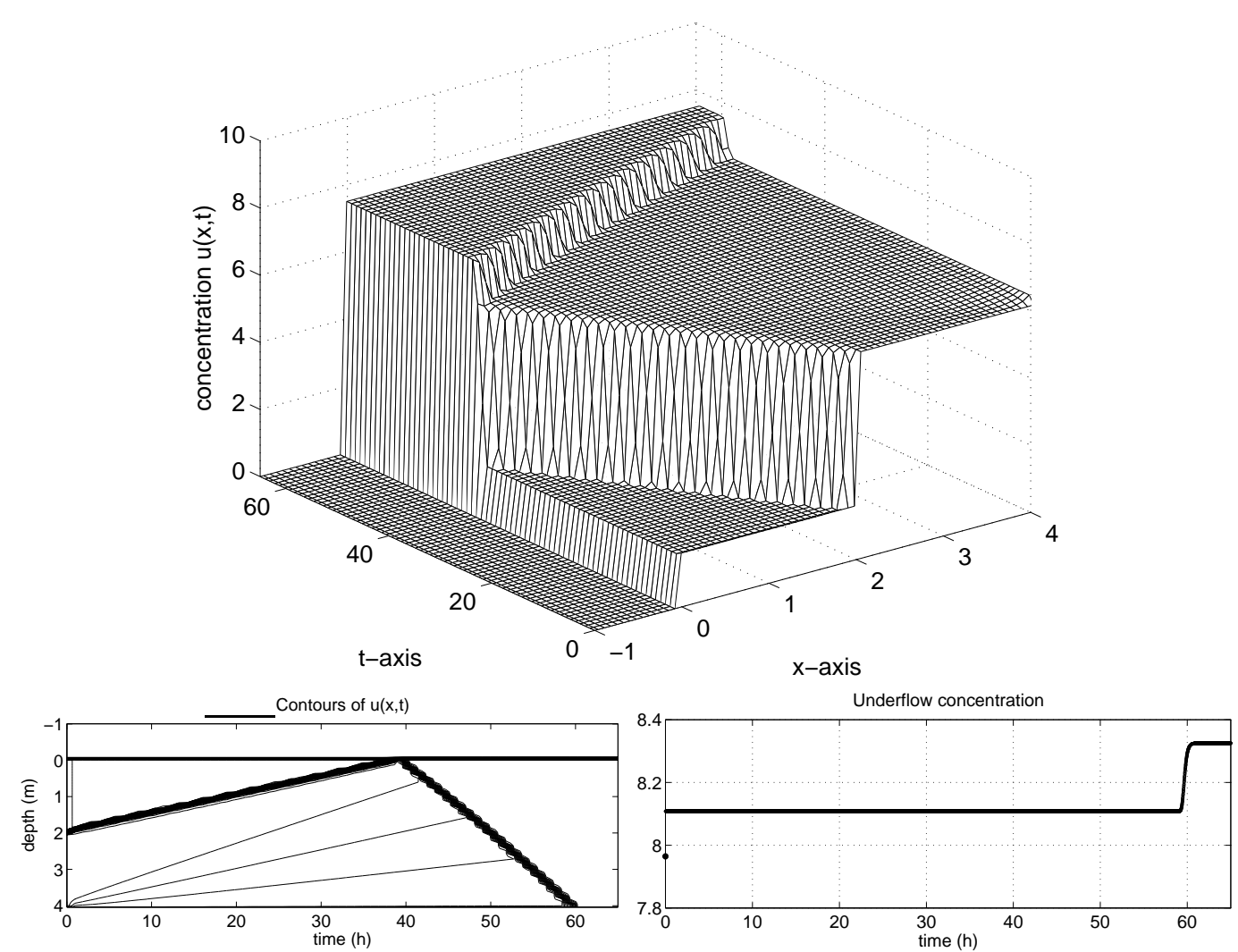

Figure 13. Numerical simulation of a response to DCL2; $\left(u_{\mathrm{f}}, s\right)=(7.5,9.5) \in \mathcal{U}_{1}\left(Q_{\mathrm{u} 0}\right) \cap \Lambda_{3} \cap \ell_{4}\left(Q_{\mathrm{u}}=3226\right)$. Initially, the solution is similar to the one in Figure 12, however, with a rising SBL instead. Optimal operation is left at about 39 hours.

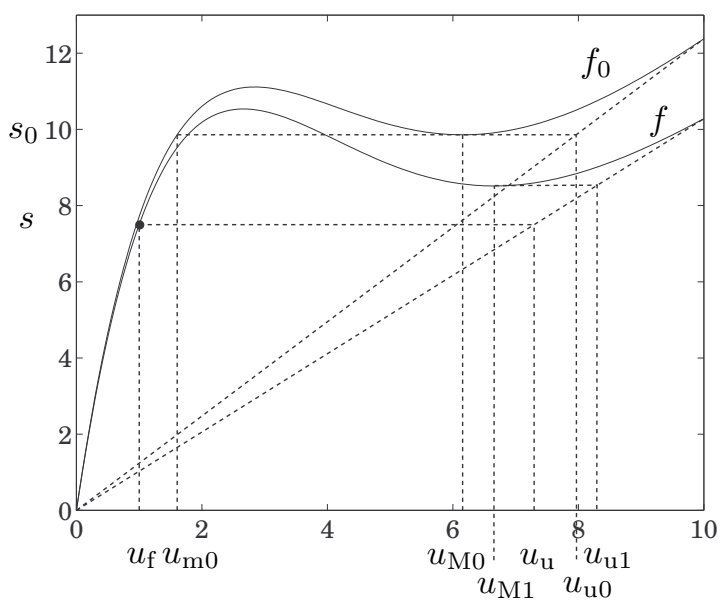

Figure 14. The feed point and fluxes in the case $\left(u_{\mathrm{f}}, s\right)=(1,7.5) \in \mathcal{U}_{1}\left(Q_{\mathrm{u} 0}\right) \cap \ell_{1}\left(Q_{\mathrm{u}}=2907\right)$. 


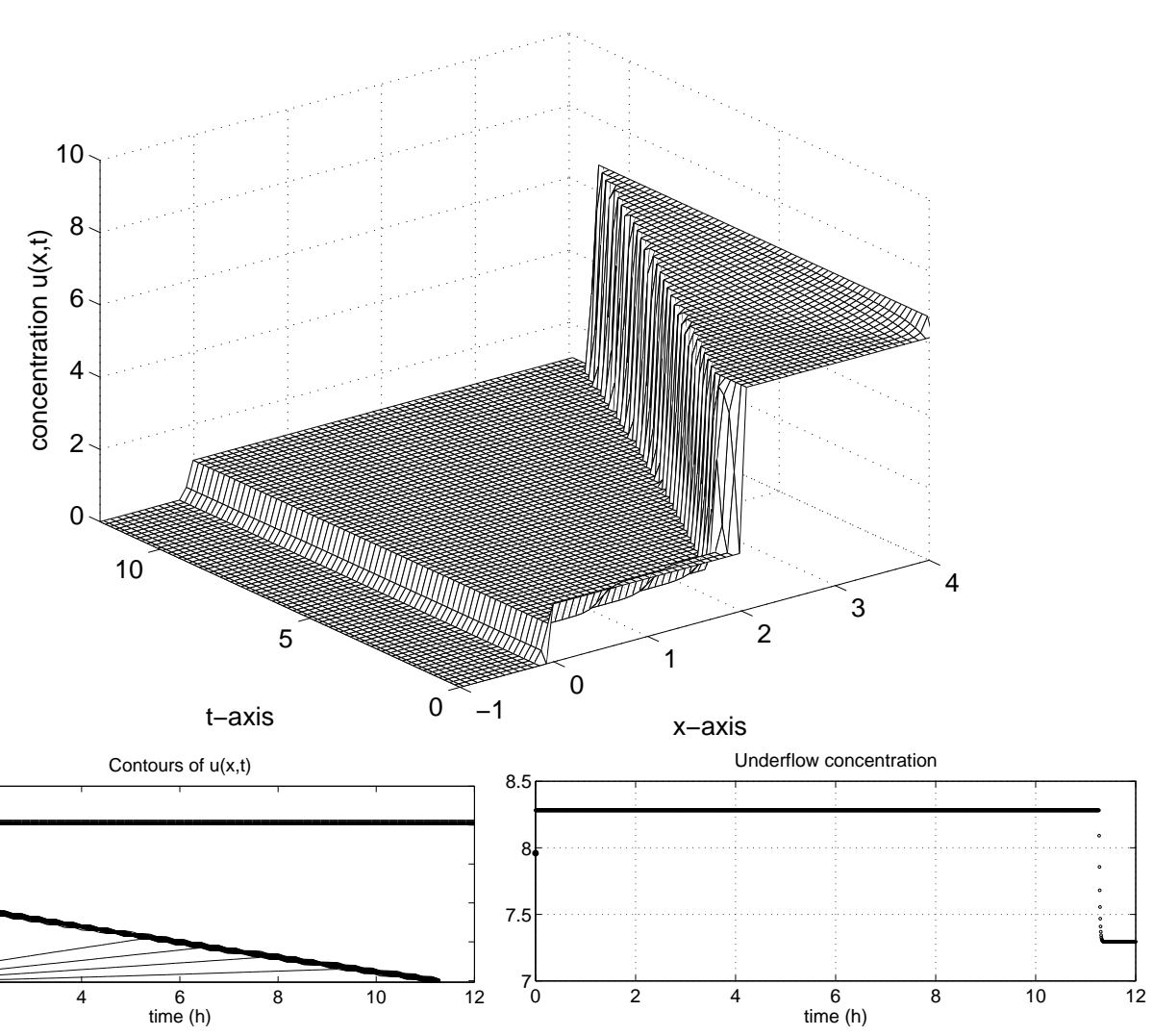

Figure 15. Numerical simulation of a response to DCL1 as $\left(u_{\mathrm{f}}, s\right)=(1,7.5) \in \mathcal{U}_{1}\left(Q_{\mathrm{u} 0}\right) \cap \ell_{1}\left(\tilde{Q}_{\mathrm{u}}=2907\right)$. Note the jump in the underflow concentration at $t=0$. Optimal operation is left at $t=11.6 \mathrm{~h}$.

\section{5. $\left(u_{\mathrm{f}}, s\right) \in\left(\mathcal{O}\left(Q_{\mathrm{u} 0}\right) \cup \ell_{4}\left(Q_{\mathrm{u} 0}\right) \cup \mathcal{U}_{2}\left(Q_{\mathrm{u} 0}\right)\right) \cap\left(P \cup \Lambda_{2} \cup \Lambda_{3}\right)$}

For the numerical demonstration we assume that $\left(u_{\mathrm{f}}, s\right)=(3,11.5) \in \mathcal{O}\left(Q_{\mathrm{u} 0}\right) \cap \Lambda_{2}$, see Figure 16. According to DCL1 we let, at $t=0, Q_{\mathrm{u}}=\ell_{2}^{-1}\left(u_{\mathrm{f}}, s\right)=\tilde{Q}_{\mathrm{u}} \approx 4298$ and hope that the settler stays in optimal operation. In fact, if the feed point were located in $\Lambda_{3 \mathrm{a}}$ we would obtain qualitatively the same solution when choosing $Q_{\mathrm{u}}=\ell_{3}^{-1}\left(u_{\mathrm{f}}, s\right)$. If $\left(u_{\mathrm{f}}, s\right) \in$ $\Lambda_{3 \mathrm{~b}} \cup P_{2}$, then, with $Q_{\mathrm{u}}=\tilde{Q}_{\mathrm{u}}$, the solution is qualitatively the same as the one presented here, but degenerate in the sense that $u_{\mathrm{m}}=u_{\mathrm{M}}=u_{\text {infl. }}$. Furthermore, the settler leaves optimal operation directly since $Q_{\mathrm{u}} \geq \overline{\bar{Q}}_{\mathrm{u}}$.

We consider first the case when the initial SBL is not too close to the bottom, see Figure 17. Note that the characteristics below $x_{5}$ all emanate from the contact discontinuity $x_{3}$ (cf. [2, Eq. (15)]). We have

$$
\begin{array}{lll}
x_{1}(t)=S_{f}\left(u_{\mathrm{m} 0}, u_{\mathrm{M} 0}\right) t+x_{\mathrm{sb} 0}=f^{\prime}\left(u_{\mathrm{M} 0}\right) t+x_{\mathrm{sb} 0}, & & 0<t<t_{2}, \\
x_{2}(t)=f^{\prime}\left(u_{\mathrm{m} 0}\right) t, & & 0<t<t_{1}, \\
x_{4}(t)=f^{\prime}\left(u_{\mathrm{m}}\right) t, & & 0<t<\tau_{1},
\end{array}
$$

from which we obtain

$$
t_{1}=\frac{x_{\mathrm{sb} 0}}{f^{\prime}\left(u_{\mathrm{m} 0}\right)-f^{\prime}\left(u_{\mathrm{M} 0}\right)}, \quad t_{2}=\frac{D-x_{\mathrm{sb} 0}}{f^{\prime}\left(u_{\mathrm{M} 0}\right)} .
$$




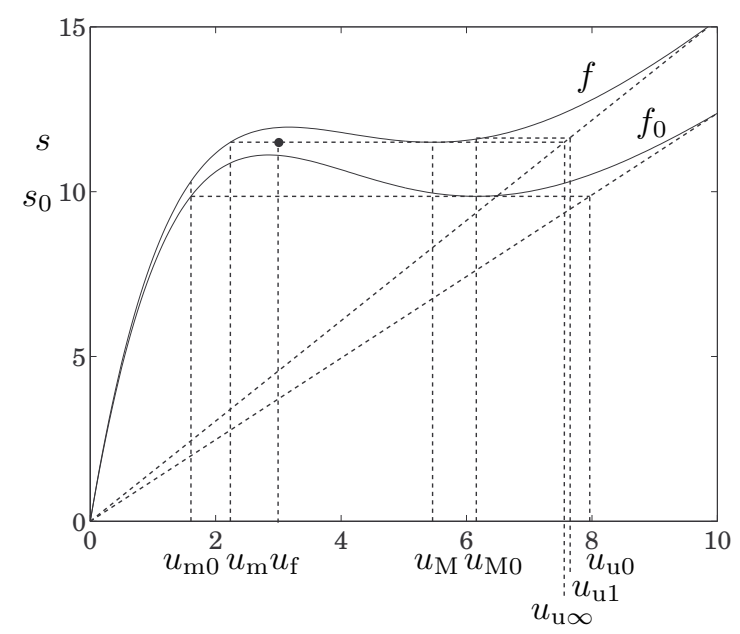

Figure 16. The feed point and flux functions in the case $\left(u_{\mathrm{f}}, s\right)=(3,11.5) \in \mathcal{O}\left(Q_{\mathrm{u} 0}\right) \cap \ell_{2}\left(Q_{\mathrm{u}}=4298\right)$.

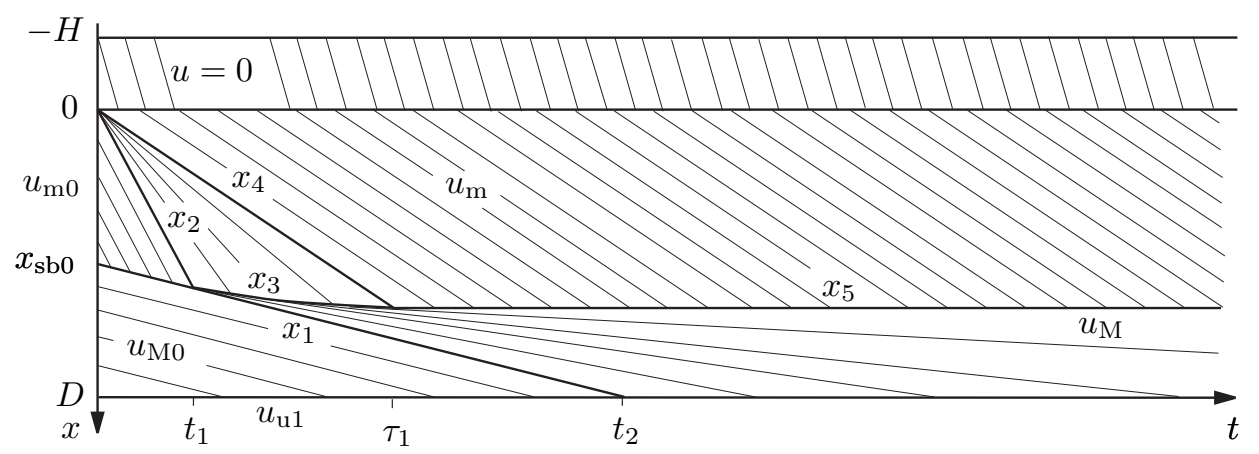

Figure 17. Solution of a response to DCL1 as $\left(u_{\mathrm{f}}, s\right) \in \mathcal{O}\left(Q_{\mathrm{u} 0}\right) \cap \ell_{2}\left(Q_{\mathrm{u}}\right)$. Note the jump in $u_{\mathrm{u}}(t)$ at $t=0$.

The underflow concentration makes a jump at $t=0$ down to $u_{\mathrm{u} 1}$ and after $t=t_{2}$ it decreases continuously to its asymptotic value $u_{\mathrm{u} \infty}$. The initial, intermediate and asymptotic underflow concentrations satisfy

$$
\begin{aligned}
& u_{\mathrm{u} 0}=\frac{f_{0}\left(u_{\mathrm{M} 0}\right)}{q_{\mathrm{u} 0}}=u_{\mathrm{M} 0}+\frac{A f_{\mathrm{b}}\left(u_{\mathrm{M} 0}\right)}{Q_{\mathrm{u} 0}}> \\
& u_{\mathrm{u} 1}=\frac{f\left(u_{\mathrm{M} 0}\right)}{q_{\mathrm{u}}}=u_{\mathrm{M} 0}+\frac{A f_{\mathrm{b}}\left(u_{\mathrm{M} 0}\right)}{Q_{\mathrm{u}}}> \\
& u_{\mathrm{u} \infty}=\frac{f\left(u_{\mathrm{M}}\right)}{q_{\mathrm{u}}}=u_{\mathrm{M}}+\frac{A f_{\mathrm{b}}\left(u_{\mathrm{M}}\right)}{Q_{\mathrm{u}}},
\end{aligned}
$$

where the first inequality follows directly from the fact that $Q_{\mathrm{u}}>Q_{\mathrm{u} 0}$ and the second follows indirectly from this fact, since $u_{\mathrm{M}}\left(Q_{\mathrm{u}}\right)$ is a decreasing function of $Q_{\mathrm{u}}$ for $Q_{\mathrm{u}}<\overline{\bar{Q}}_{\mathrm{u}}\left(\Leftrightarrow u_{\mathrm{M}}>\right.$ $\left.u_{\text {infl }}\right)$ and $f_{\mathrm{b}}(u)$ is decreasing for $u>u_{\text {infl. }}$. The mass decreases according to

$$
m(t)= \begin{cases}m_{0}+t\left(A s-Q_{\mathrm{u}} u_{\mathrm{u} 1}\right), & 0 \leq t \leq t_{2} \\ m_{0}+t_{2}\left(A s-Q_{\mathrm{u}} u_{\mathrm{u} 1}\right)+\int_{t_{2}}^{t}\left(A s-Q_{\mathrm{u}} u_{\mathrm{u}}(\tau)\right) d \tau, & t \geq t_{2},\end{cases}
$$

where we note that $A s=Q_{\mathrm{u}} u_{\mathrm{u} \infty}<Q_{\mathrm{u}} u_{\mathrm{u}}(\tau) \forall \tau \geq t_{2}$. 
Since the contact discontinuity $x_{3}(t)$ can only be obtained numerically generally, there is neither an explicit expression for $\tau_{1}$ nor for the new SBL, $x_{\mathrm{sb}}=x_{5}$. This constant lies between $x_{1}\left(t_{1}\right)=x_{2}\left(t_{1}\right)$ and the intersection of $x_{1}$ and a prolongation of $x_{4}$, which occurs at

$$
\tau_{2} \equiv \frac{x_{\mathrm{sb} 0}}{f^{\prime}\left(u_{\mathrm{m}}\right)-f^{\prime}\left(u_{\mathrm{M} 0}\right)}>\tau_{1} .
$$

Hence, we have the following estimate for the new SBL:

$$
\frac{x_{\mathrm{sb} 0}}{1-f^{\prime}\left(u_{\mathrm{M} 0}\right) / f^{\prime}\left(u_{\mathrm{m} 0}\right)}=x_{1}\left(t_{1}\right)<x_{\mathrm{sb}}<x_{1}\left(\tau_{2}\right)=\frac{x_{\mathrm{sb} 0}}{1-f^{\prime}\left(u_{\mathrm{M} 0}\right) / f^{\prime}\left(u_{\mathrm{m}}\right)} .
$$

The asymptotic relationship between the mass and the new sludge blanket level, $m_{\infty}=$ $A\left(u_{\mathrm{M}} D-x_{\mathrm{sb}}\left(u_{\mathrm{M}}-u_{\mathrm{m}}\right)\right)$, can then be used to estimate the new mass.

Numerical values corresponding to Figure 16 and obtained by the formulae above are

$$
\begin{array}{lll}
u_{\mathrm{f}}=3 \mathrm{~kg} / \mathrm{m}^{3} & u_{\mathrm{M} 0}=6.16 \mathrm{~kg} / \mathrm{m}^{3} & t_{1}=0.8 \mathrm{~h} \\
s=11.5 \mathrm{~kg} /\left(\mathrm{m}^{2} \mathrm{~h}\right) & u_{\mathrm{M}}=5.46 \mathrm{~kg} / \mathrm{m}^{3} & t_{2}=7.1 \mathrm{~h} \\
Q_{\mathrm{u} 0}=3500 \mathrm{~m}^{3} / \mathrm{h} & u_{\mathrm{u} 0}=7.96 \mathrm{~kg} / \mathrm{m}^{3} & \tau_{2}=2.3 \mathrm{~h} \\
Q_{\mathrm{u}}=4298 \mathrm{~m}^{3} / \mathrm{h} & u_{\mathrm{u} 1}=7.63 \mathrm{~kg} / \mathrm{m}^{3} & 2.2 \mathrm{~m}=1.1 x_{\mathrm{sb} 0}<x_{\mathrm{sb}} \\
u_{\mathrm{m} 0}=1.61 \mathrm{~kg} / \mathrm{m}^{3} & u_{\mathrm{u} \infty}=7.56 \mathrm{~kg} / \mathrm{m}^{3} & <1.3 x_{\mathrm{sb} 0}=2.7 \mathrm{~m} \quad \text { Eq. (8) } \\
u_{\mathrm{m}}=2.23 \mathrm{~kg} / \mathrm{m}^{3} & &
\end{array}
$$

A numerical simulation is shown in Figure 18.

Suppose now that the initial sludge blanket is located near the bottom, such that SBL reaches the bottom before $\tau_{1}$. Then lower concentrations than $u_{\mathrm{m}}$ reach the bottom and Condition $\Gamma$ implies that the underflow concentration will be lower than the previous value $u_{\mathrm{u} \infty}$ shown in Figure 16. In such a case the solution can be described (qualitatively) by cutting off the solution shown in Figure 17 at a level between $x=x_{\mathrm{sb} 0}$ and $x=x_{5}$ and defining the cutting level as the new bottom level. The boundary concentrations at the bottom all imply, by [2, Eq. (6)], that there is no wave (characteristic or discontinuity) emanating from the bottom upwards. To demonstrate this we perform a simulation with the same data as above except that we let $x_{\mathrm{sb} 0}=3.75 \mathrm{~m}$, see Figure 19. In this example the SBL reaches the bottom without any interaction with $x_{2}$. This implies that the bottom concentration is $u_{D}=u_{\mathrm{m} 0}$ and, by [2, Eq. (6)] and (4), that the underflow concentration $f\left(u_{\mathrm{m} 0}\right) / q_{\mathrm{u}}=6.87 \mathrm{~kg} / \mathrm{m}^{3}$ (at $t \approx 1 \mathrm{~h}$ ) is lower than the asymptotic value $u_{\mathrm{u} \infty}=7.56 \mathrm{~kg} / \mathrm{m}^{3}$.

In the latter circumstances the settler cannot be kept in optimal operation by performing this type of direct control action. Since we cannot compute $x_{3}$ or $\tau_{1}$ exactly, a safe margin above the bottom for the SBL is obtained if the initial one satisfies

$$
x_{1}\left(\tau_{2}\right) \leq D \quad \Longleftrightarrow \quad x_{\mathrm{sb} 0} \leq\left(1-\frac{f^{\prime}\left(u_{\mathrm{M} 0}\right)}{f^{\prime}\left(u_{\mathrm{m}}\right)}\right) D,
$$

which yields $x_{\mathrm{sb} 0} \leq 0.76 D=3.04 \mathrm{~m}$ with the present data. Numerical simulations yield that the actual boundary depth is $3.32 \mathrm{~m}$.

Consider DCL2, which differs from DCL1 only if $\left(u_{\mathrm{f}}, s\right) \in \Lambda_{3}$ in the sense that $Q_{\mathrm{u}}$ is then set to the slightly lower value $\tilde{Q}_{\mathrm{u}}$ such that $\left(u_{\mathrm{f}}, s\right) \in \ell_{4}\left(\tilde{Q}_{\mathrm{u}}\right)$. This means that the settler is critically loaded, but optimal operation cannot be maintained in the new steady state. The solution is then as the one in [2, case $\left.\mathcal{U}_{2 \mathrm{a}}, s<f\left(u_{0}^{\mathrm{M}}\right)\right]$. (If $\left(u_{\mathrm{f}}, s\right) \in \mathcal{U}_{2 \mathrm{a}}$, i.e., the feed point lies below the graph of $f$, then $Q_{\mathrm{u}}$ is actually slightly less than $Q_{\mathrm{u} 0}$.) If the SBL lies close to the bottom, DCL2 may be advantageous over DCL1 since optimal operation may not be 


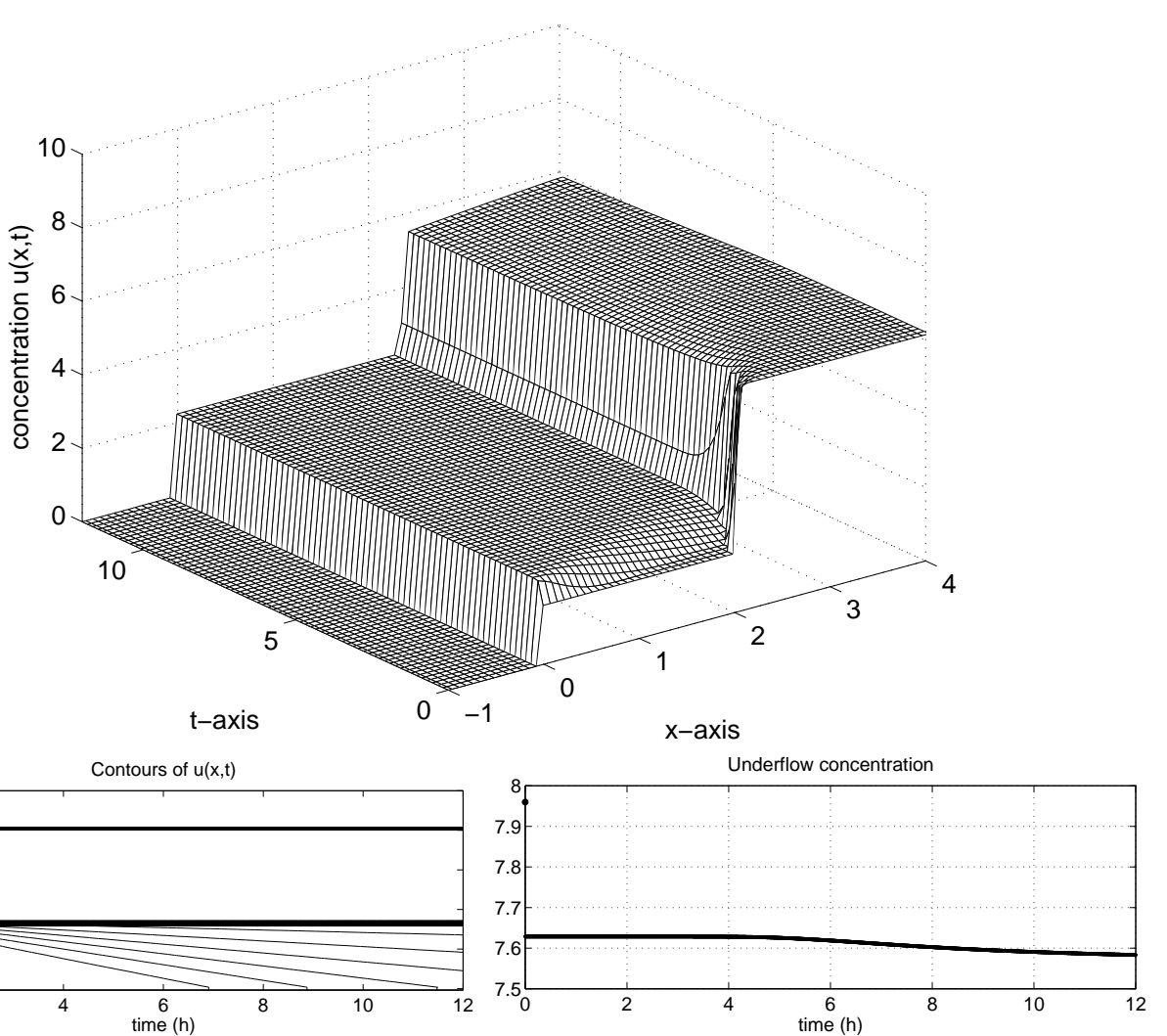

Figure 18. Numerical simulation of a response to DCL1 as $\left(u_{\mathrm{f}}, s\right) \in \mathcal{O}\left(Q_{\mathrm{u} 0}\right) \cap \ell_{2}\left(Q_{\mathrm{u}}\right)$. Note the jump in $u_{\mathrm{u}}(t)$ at $t=0$.

left after a short time. However, in such a case it is easier to wait with any control action, see Section 7.

\section{6. $\left(u_{\mathrm{f}}, s\right) \in \mathcal{O}\left(Q_{\mathrm{u} 0}\right) \cap \Lambda_{1}$}

Strategy DCL1 (= DCL2 = DCL3) means that $Q_{\mathrm{u}}=\tilde{Q}_{\mathrm{u}}>Q_{\mathrm{u} 0}$ is chosen such that $\left(u_{\mathrm{f}}, s\right) \in$ $\ell_{1}\left(Q_{\mathrm{u}}\right)$. Suppose first that $Q_{\mathrm{u}}<\overline{\bar{Q}}_{\mathrm{u}}$. We obtain a solution that differs only slightly from the one in Figure 17. Compared to Figure 16 the feed point is now located on the graph of $f$ to the left of $u_{\mathrm{m}}$. The underflow concentration jumps directly down to $u_{\mathrm{u} 1}=f\left(u_{\mathrm{M} 0}\right) / q_{\mathrm{u}}$. The concentration on the right of $x_{4}$ is $u_{\mathrm{f}}<u_{\mathrm{m}}$ and $s=f\left(u_{\mathrm{f}}\right)<f\left(u_{\mathrm{m}}\right)=f\left(u_{\mathrm{M}}\right)$ holds. (Note that $s$ may be less or greater than $s_{0}$.) This implies that $u_{\mathrm{f}}^{*}>u_{\mathrm{M}}$ and the discontinuity $x_{5}$ has the positive speed $x_{5}^{\prime}(t)=S_{f}\left(u_{\mathrm{f}}, u_{\mathrm{f}}^{*}\right)=f^{\prime}\left(u_{\mathrm{f}}^{*}\right)$. Hence, $x_{5}$ will reach the bottom at a finite time point, at which the underflow concentration makes a jump down to $u_{\mathrm{u} \infty}=f\left(u_{\mathrm{f}}\right) / q_{\mathrm{u}}=$ $s / q_{\mathrm{u}}$. A numerical simulation in the case $\left(u_{\mathrm{f}}, s\right)=(1.8,11.0)$ is shown in Figure 20.

If $Q_{\mathrm{u}} \geq \overline{\bar{Q}}_{\mathrm{u}}$, the solution will qualitatively be the same with $u_{\mathrm{m}}=u_{\mathrm{M}}=u_{\mathrm{infl}}$, however, optimal operation is left immediately by definition. 


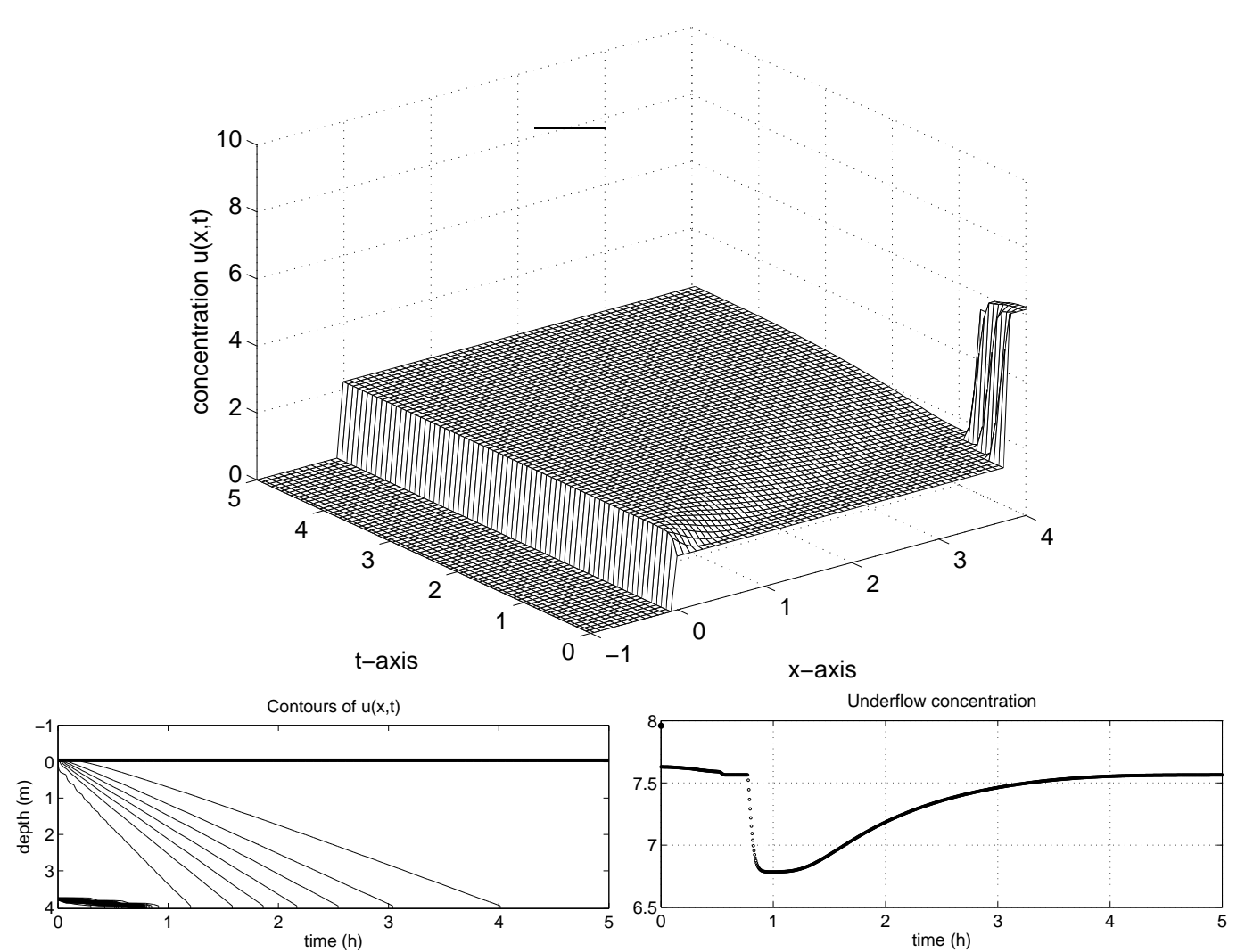

Figure 19. Numerical simulation of a response to DCL1 as $\left(u_{\mathrm{f}}, s\right) \in \mathcal{O}\left(Q_{\mathrm{u} 0}\right) \cap \ell_{2}\left(Q_{\mathrm{u}}\right)$ and with an initial sludge blanket near the bottom. Note the dip in the underflow concentration as the SBL reaches the bottom.
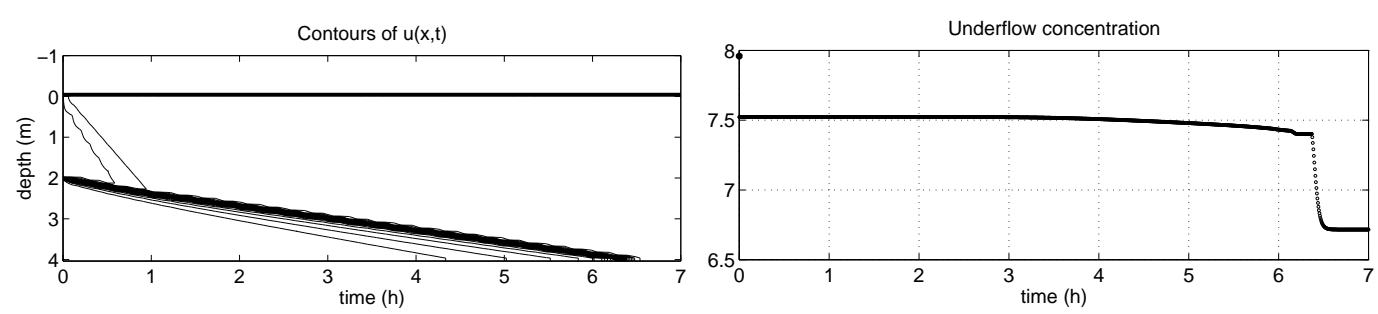

Figure 20. Numerical simulation of a response to DCL1 as $\left(u_{\mathrm{f}}, s\right)=(1.8,11.0) \in \mathcal{O}\left(Q_{\mathrm{u} 0}\right) \cap \ell_{1}\left(Q_{\mathrm{u}}\right)$ with $Q_{\mathrm{u}}<\overline{\bar{Q}}_{\mathrm{u}}$. Optimal operation is left after $6.5 \mathrm{~h}$.

\section{7. $\left(u_{\mathrm{f}}, s\right) \in \Lambda_{\mathrm{a}}^{\prime}$}

To keep optimal operation as long as possible, the best remedy is to increase the control variable as much as possible, i.e., to set $Q_{\mathrm{u}}=Q_{\mathrm{f}} \Leftrightarrow Q_{\mathrm{e}}=0$. This is strategy DCL1. Then we obtain the slowest possible rising SBL, see the simulation in Figure 21.

There will not be any sludge blanket in the new steady state, which arises after a finite time. The solution is similar to the one constructed in [2, Fig. 21], however, with a sinking SBL before $t_{1}$ (as in Figure 17) and with $u_{2}$ replaced by $u_{\mathrm{f}}$ as the new concentration in the thickening zone. The boundary concentration below the feed inlet is not $u_{\mathrm{m}}$ but higher. Since $s \leq f\left(u^{\mathrm{M}}\right)$ (definition of $\Lambda_{\mathrm{a}}^{\prime}$ ) the initial boundary concentration below the feed level is $u_{1}$, defined by $s=f\left(u_{1}\right)$ and $u_{\mathrm{m}}<u_{1} \leq u^{\mathrm{M}}$, cf. in [2, Fig. 20 (left)]. (Note that on the boundary 

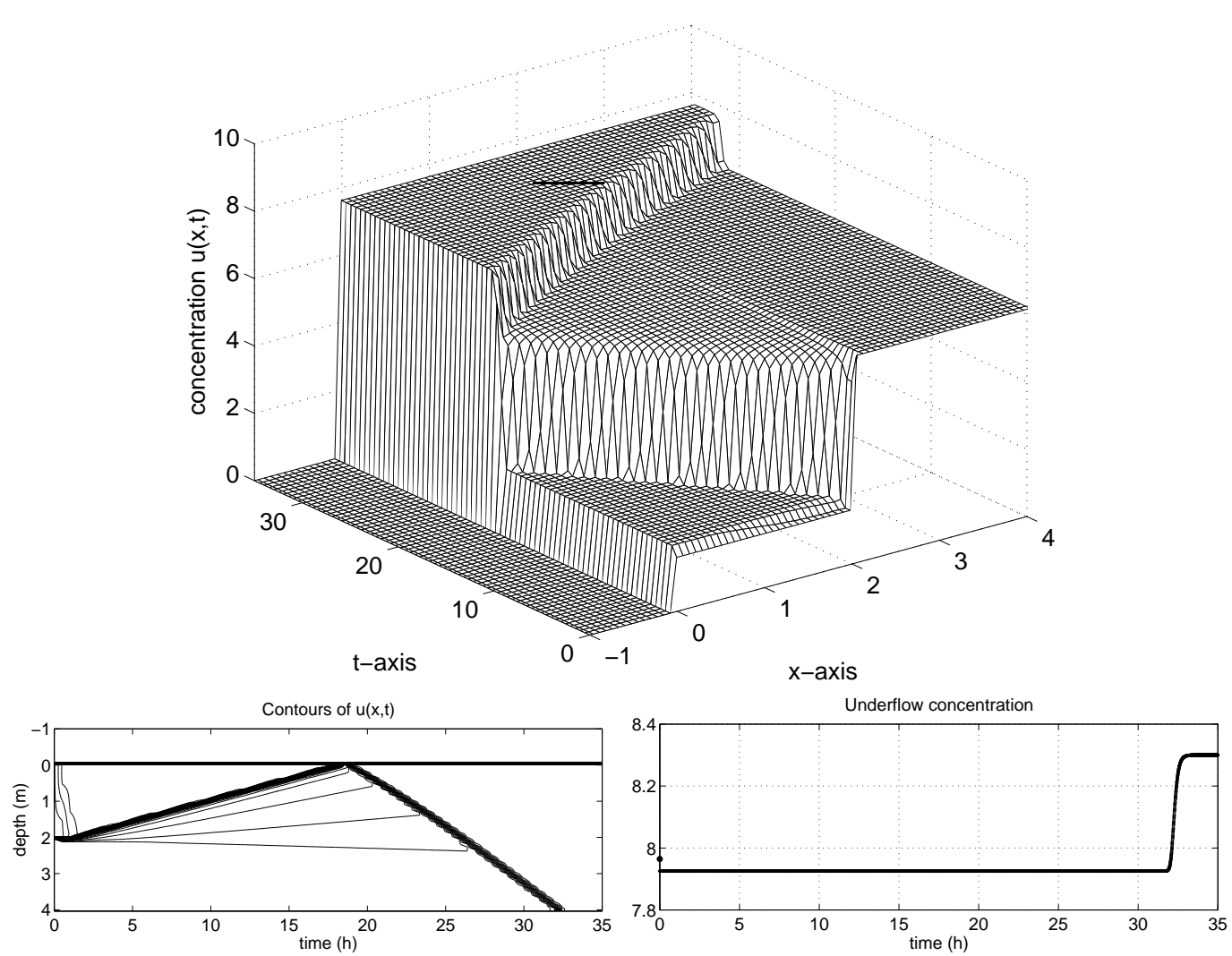

Figure 21. Numerical simulation of a response to DCL1 as $\left(u_{\mathrm{f}}, s\right)=(8.3,10.5) \in \Lambda_{\mathrm{a}}^{\prime} \cap \mathcal{U}_{2}\left(Q_{\mathrm{u} 0}=3500\right)$ with $Q_{\mathrm{u}}=Q_{\mathrm{f}}=3577 \mathrm{~m}^{3} / \mathrm{h}$. The pure liquid in the clarification zone is still $\left(Q_{\mathrm{e}}=0\right)$. Optimal operation is left after $18 \mathrm{~h}$. The settler is slightly underloaded and after $t \approx 33 \mathrm{~h} u_{\mathrm{u}}=u_{\mathrm{f}}$ holds.
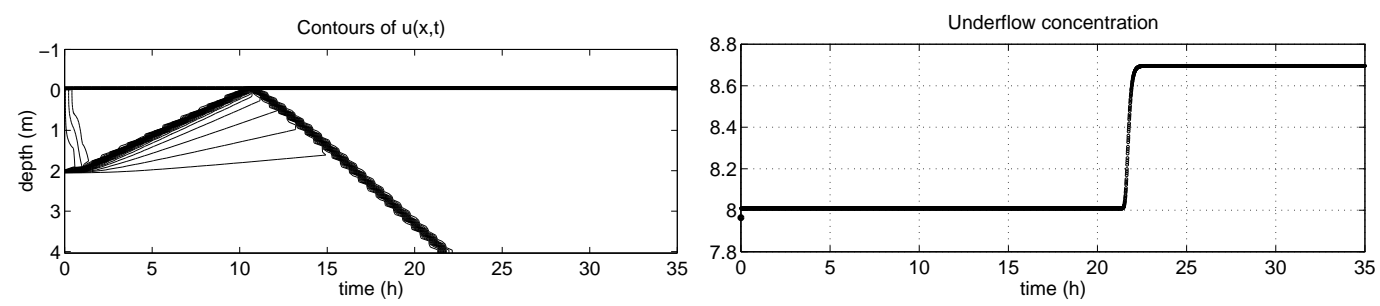

Figure 22. Numerical simulation of a response to strategy DCL2 as $\left(u_{\mathrm{f}}, s\right)=(8.3,10.5) \in \Lambda_{\mathrm{a}}^{\prime} \cap \mathcal{U}_{2}\left(Q_{\mathrm{u} 0}=3500\right) \cap \ell_{4}\left(\tilde{Q}_{\mathrm{u}}=3414\right)$. Optimal operation is left after $11 \mathrm{~h}$. In the new steady state the settler is critically loaded with $u_{\mathrm{u}}=8.7 \mathrm{~kg} / \mathrm{m}^{3}$.

between $\Lambda_{\mathrm{a}}^{\prime}$ and $\Lambda_{\mathrm{b}}^{\prime}, s=f\left(u^{\mathrm{M}}\right) \Leftrightarrow u_{1}=u^{\mathrm{M}}$ holds and the initial expansion wave from the feed level reaches up to the feed level.) The rising sludge blanket has the negative speed $S_{f}\left(u_{1}, u_{1}^{*}\right)$. After it has reached the feed level (at $t \approx 18$ in Figure 21 ) the new boundary concentration below the feed level is $u_{2}>u_{\mathrm{M} 0}$ ([2, Fig. 20 (right)]), and this is eventually spread all over the thickening zone.

As a comparison, we show in Figure 22 the simulation in the case strategy DCL2 is invoked: the control variable is set to $Q_{\mathrm{u}}=\ell_{4}^{-1}\left(u_{\mathrm{f}}, s\right)=\tilde{Q}_{\mathrm{u}}=3414$. Clearly, optimal operation is left earlier than in Figure 21. 


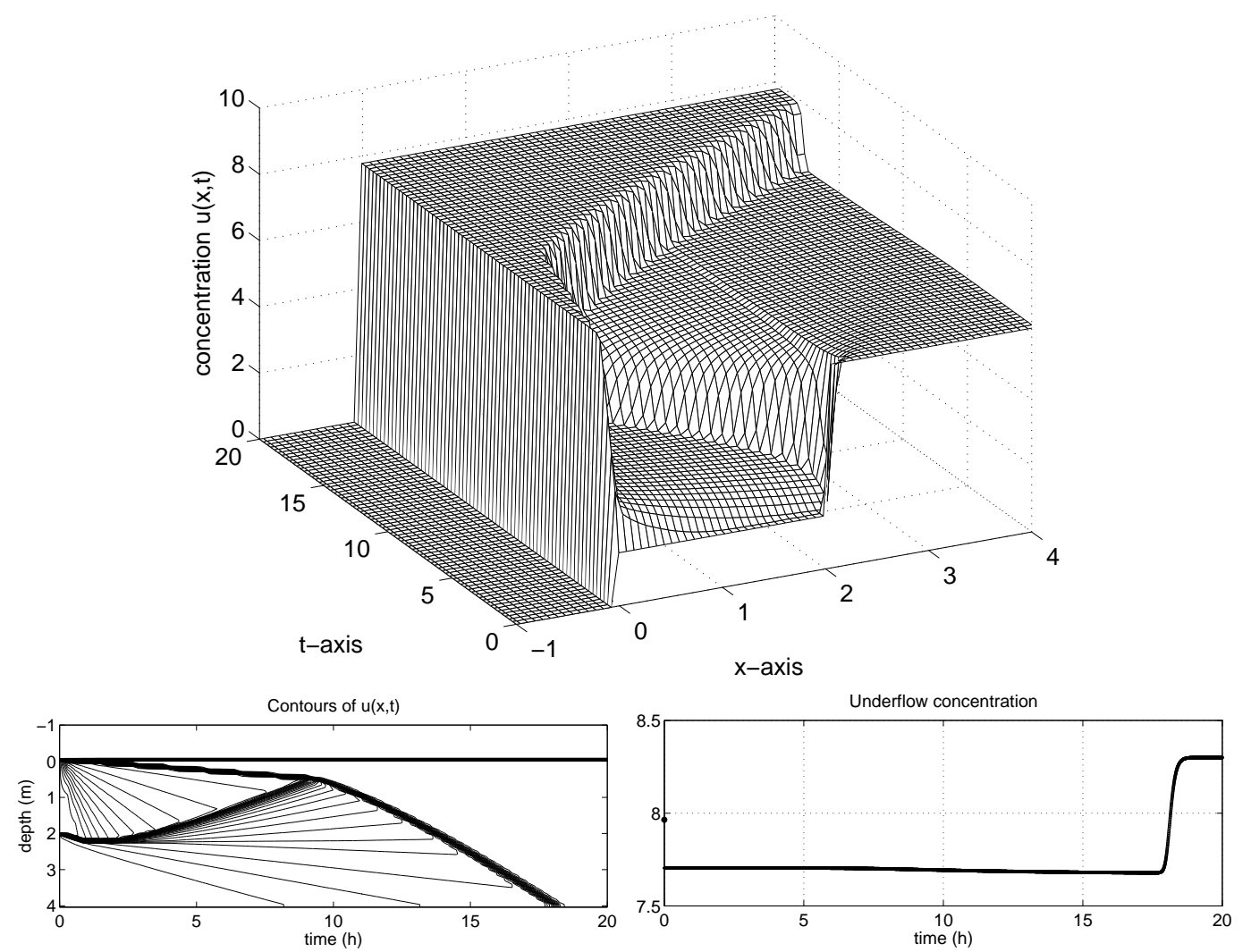

Figure 23. Numerical simulation of a response to DCL1 as $\left(u_{\mathrm{f}}, s\right)=(8.3,12.0) \in \Lambda_{\mathrm{b}}^{\prime} \cap \mathcal{O}\left(Q_{\mathrm{u} 0}\right)$ and $Q_{\mathrm{u}}=Q_{\mathrm{f}}=4088 \mathrm{~m}^{3} / \mathrm{h}$. Note that the new underflow concentration, after $18 \mathrm{~h}$, is $u_{\mathrm{u}}=u_{\mathrm{f}}=8.3 \mathrm{~kg} / \mathrm{m}^{3}$.

\section{8. $\left(u_{\mathrm{f}}, s\right) \in \Lambda_{\mathrm{b}}^{\prime}$}

By analogy with Section 6.7 the best remedy (to keep optimal operation as long as possible) is to let $Q_{\mathrm{u}}=Q_{\mathrm{f}}$, which corresponds to DCL1 = DCL2 = DCL3. Since $s>f\left(u^{\mathrm{M}}\right)$ the new boundary concentration below the feed level is the high concentration $u_{\mathrm{f}}>u_{\text {infl }}$ directly, cf. [2, Fig. 23]. Optimal operation is therefore left immediately. The solution is demonstrated by the numerical simulation in Figure 23. Compare with the solution in [2, Fig. 25].

\section{Optimal control strategies of step inputs}

\subsection{OPERATING CHART FOR OPTIMAL CONTROL OF STEP INPUTS}

Given a settler in optimal operation in steady state and a step input, we have in [2] seen the response without any control action, and in Section 6 the response to a direct control action. With this information we can obtain optimal control strategies with respect to the control objectives CO1-CO3 defined in Section 4. Therefore, we combine the information in the operating chart for direct control of step responses in Figure 6 with the operating chart for step responses and the safe and dangerous regions, see Figure 24 here and [2, Theorem 4.1]. Since the settler is not in optimal operation when $Q_{\mathrm{u}} \geq \bar{Q}_{\mathrm{u}}$, see for example Section 6.6, we 

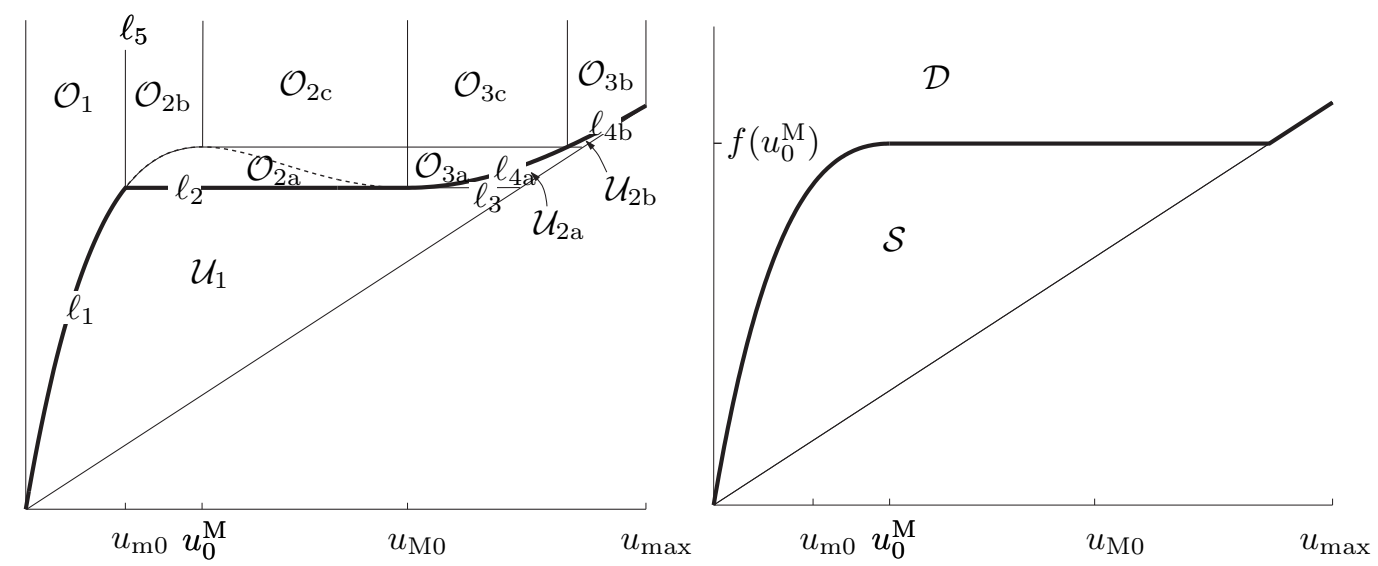

Figure 24. Operating charts from [2] shown with the initial value $Q_{\mathrm{u} 0}$. Left: Operating chart for step responses from optimal operation. Right: The 'dangerous' and 'safe' regions of the operating chart corresponding to whether optimal operation is left immediately or not after a step input. Referring to the control objects in Section 4 note that $L_{3}=\partial \mathcal{S} \cap \partial \mathcal{D}$.

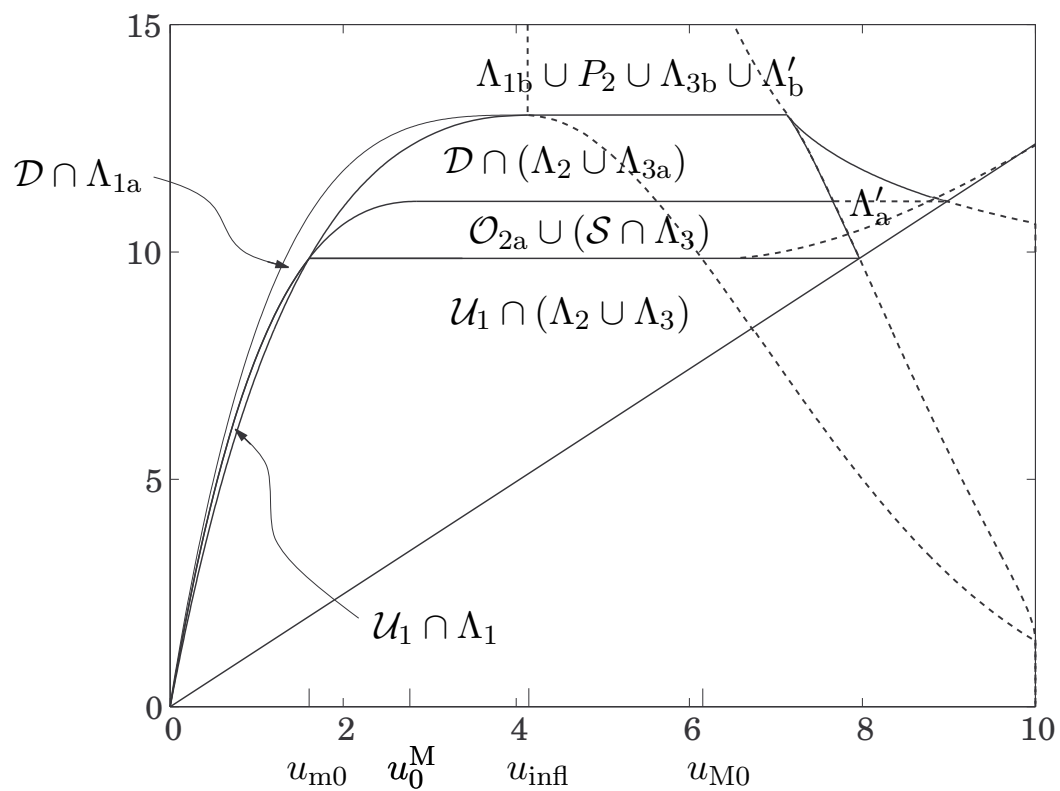

Figure 25. Operating chart for optimal control of step inputs. The regions are shown by solid lines. The sets refer to the initial value $Q_{\mathrm{u} 0}$, i.e., $\mathcal{D} \equiv \mathcal{D}\left(Q_{\mathrm{u} 0}\right)$ etc. Given a step change with $\left(u_{\mathrm{f}}, s\right)$ in a region, the optimal control strategies are shown in Table II.

have to divide $\Lambda_{1}$ into two disjoint subsets, by analogy with the division of $\Lambda_{3}$, see (3):

$$
\Lambda_{1 \mathrm{a}}=\Lambda_{1} \cap\left\{(u, y): y<f_{\mathrm{b}}(u)+\overline{\bar{q}}_{\mathrm{u}} u\right\} \quad \text { and } \quad \Lambda_{1 \mathrm{~b}}=\Lambda_{1} \backslash \Lambda_{1 \mathrm{a}} .
$$

The resulting operating chart is shown in Figure 25 and in Table II we give an overview of the optimal control strategies. For $\mathrm{CO} 2$ and $\mathrm{CO} 3$ a lower bound $u_{\mathrm{u}}^{\min }$ on the underflow concentration is prescribed. It is reasonable to assume that $u_{\mathrm{u}}^{\min } \leq u_{\mathrm{u} 0}$ holds. Unless otherwise stated, we therefore assume that $u_{\mathrm{u}}^{\mathrm{min}}=u_{\mathrm{u} 0}$ holds as the worst case. In the following sections we comment upon the optimal strategies in Table II for each region. 
Table II. Survey of optimal strategies for control of step inputs. Each case should be read from the left to the right. 'Optimal operation maintained until' refers to the control action stated in the adjacent left column. 'Delayed' means that a single step-control action is performed at a later time point. PCC is specified in the text in each case.

\begin{tabular}{|c|c|c|c|c|c|}
\hline $\begin{array}{l}\text { Region in op- } \\
\text { erating chart } \\
\text { (Figure 25) }\end{array}$ & $\begin{array}{l}\text { Optimal control } \\
\text { action to meet } \\
\mathrm{CO1} \text { and first } \\
\text { action of } \mathrm{CO2}\end{array}$ & $\begin{array}{l}\text { Optimal operation } \\
\text { maintained until }\end{array}$ & $\begin{array}{l}\text { Second } \\
\text { control } \\
\text { action to } \\
\text { meet } \mathrm{CO} 2\end{array}$ & $\begin{array}{l}\text { Optimal } \\
\text { control } \\
\text { action to } \\
\text { meet } \mathrm{CO3}\end{array}$ & $\begin{array}{l}\text { Optimal } \\
\text { operation } \\
\text { maintained } \\
\text { until }\end{array}$ \\
\hline$\left(\ell_{1} \cup \mathcal{U}_{1}\right) \cap \Lambda_{1}$ & DCL1 & SBL meets bottom & PCC & PCC & $\begin{array}{l}\text { third control } \\
\text { action }\end{array}$ \\
\hline $\begin{array}{l}\mathcal{U}_{1} \cap\left(P \cup \Lambda_{2} \cup\right. \\
\left.\Lambda_{3}\right)\end{array}$ & $\begin{array}{l}\text { DCL1 or delayed } \\
\text { L1 }\end{array}$ & $t=\infty$ & none & $\begin{array}{l}\text { DCL1 or } \\
\text { delayed L1 }\end{array}$ & $t=\infty$ \\
\hline $\mathcal{O}_{2 \mathrm{a}} \cup\left(\mathcal{S} \cap \Lambda_{3}\right)$ & $\begin{array}{l}\text { DCL1 if (9) is true, } \\
\text { else delayed L1 }\end{array}$ & $t=\infty$ & none & delayed L1 & $\begin{array}{l}\text { SBL meets } \\
\text { feed level }\end{array}$ \\
\hline \multirow[t]{3}{*}{$\mathcal{D} \cap\left(\Lambda_{2} \cup \Lambda_{3 a}\right)$} & (9) is true: DCL1 & $t=\infty$ if (9) is true & none & \multirow[t]{3}{*}{ PCC } & \multirow[t]{3}{*}{$\begin{array}{l}t=0 \text { if } \\
u_{\mathrm{u}}^{\min }=u_{0}\end{array}$} \\
\hline & \multirow[t]{2}{*}{$\begin{array}{l}\text { (9) is false: DCL3. } \\
\text { If SBL does not } \\
\text { meet bottom, 2nd } \\
\text { action to meet CO1: } \\
\text { L1 }\end{array}$} & $\begin{array}{l}\text { SBL does not meet } \\
\text { bottom: } t=\infty\end{array}$ & L1 & & \\
\hline & & SBL meets bottom & PCC & & \\
\hline$\Lambda_{\mathrm{a}}^{\prime}$ & DCL1 & $\begin{array}{l}\text { SBL meets feed } \\
\text { level }\end{array}$ & $\begin{array}{l}Q_{\mathrm{u}}=Q_{\mathrm{u} 0} \\
\text { if }\left(u_{\mathrm{f}}, s\right) \in \\
\mathcal{S}, \text { else L3 }\end{array}$ & delayed L2 & $\begin{array}{l}\text { SBL meets } \\
\text { feed level if } \\
\left(u_{\mathrm{f}}, s\right) \in \mathcal{S}, \\
\text { else } t=0\end{array}$ \\
\hline $\mathcal{D} \cap \Lambda_{1 \mathrm{a}}$ & DCL1 & SBL meets bottom & PCC & delayed L1 & $t=0$ \\
\hline $\begin{array}{l}\Lambda_{1 \mathrm{~b}} \cup P_{2} \cup \\
\Lambda_{3 \mathrm{~b}} \cup \Lambda_{\mathrm{b}}^{\prime}\end{array}$ & $\begin{array}{l}\text { CO1: DCL1; } \\
\text { CO2: see CO3 }\end{array}$ & $t=0$ & none & delayed L1 & $t=0$ \\
\hline
\end{tabular}

7.2. $\left(u_{\mathrm{f}}, s\right) \in\left(\ell_{1}\left(Q_{\mathrm{u} 0}\right) \cup \mathcal{U}_{1}\left(Q_{\mathrm{u} 0}\right)\right) \cap \Lambda_{1}$

Without any control action the sludge blanket will decrease and after a finite time reach the bottom, see $[2$, Sections $4.2,4.4]$. Note that DCL1 $=\operatorname{DCL} 2\left(Q_{\mathrm{u}}\right.$ is decreased to $\left.\tilde{Q}_{\mathrm{u}}\right)$. This control action results in the slowest possible decrease of the SBL and implies that CO1 is fulfilled. A critically loaded settler is obtained as shown in Section 6.4. Since $Q_{\mathrm{u}}$ is decreased, $u_{\mathrm{u}}(t)=u_{\mathrm{u} 0}=u_{\mathrm{u}}^{\min }$ holds until the SBL reaches the bottom, i.e., as long as optimal operation is maintained. Therefore, $\mathrm{CO} 2$ and $\mathrm{CO} 3$ are equivalent. After the SBL has reached the bottom, the underflow concentration drops below $u_{\mathrm{u} 0}$. To fulfil $\mathrm{CO} 2$, Theorem 4.1 yields that $Q_{\mathrm{u}}$ should be lowered further to $Q_{\mathrm{u}}^{\max 1}$ just before the SBL reaches the bottom. Then there will be a rising discontinuity in the clarification zone. Just before this one reaches the effluent level, $Q_{\mathrm{u}}$ should be set back to $\tilde{Q}_{\mathrm{u}}$ to keep $u_{\mathrm{e}}=0$ and satisfy $\mathrm{CO} 2$ and CO3. This is demonstrated in Figure 26. 

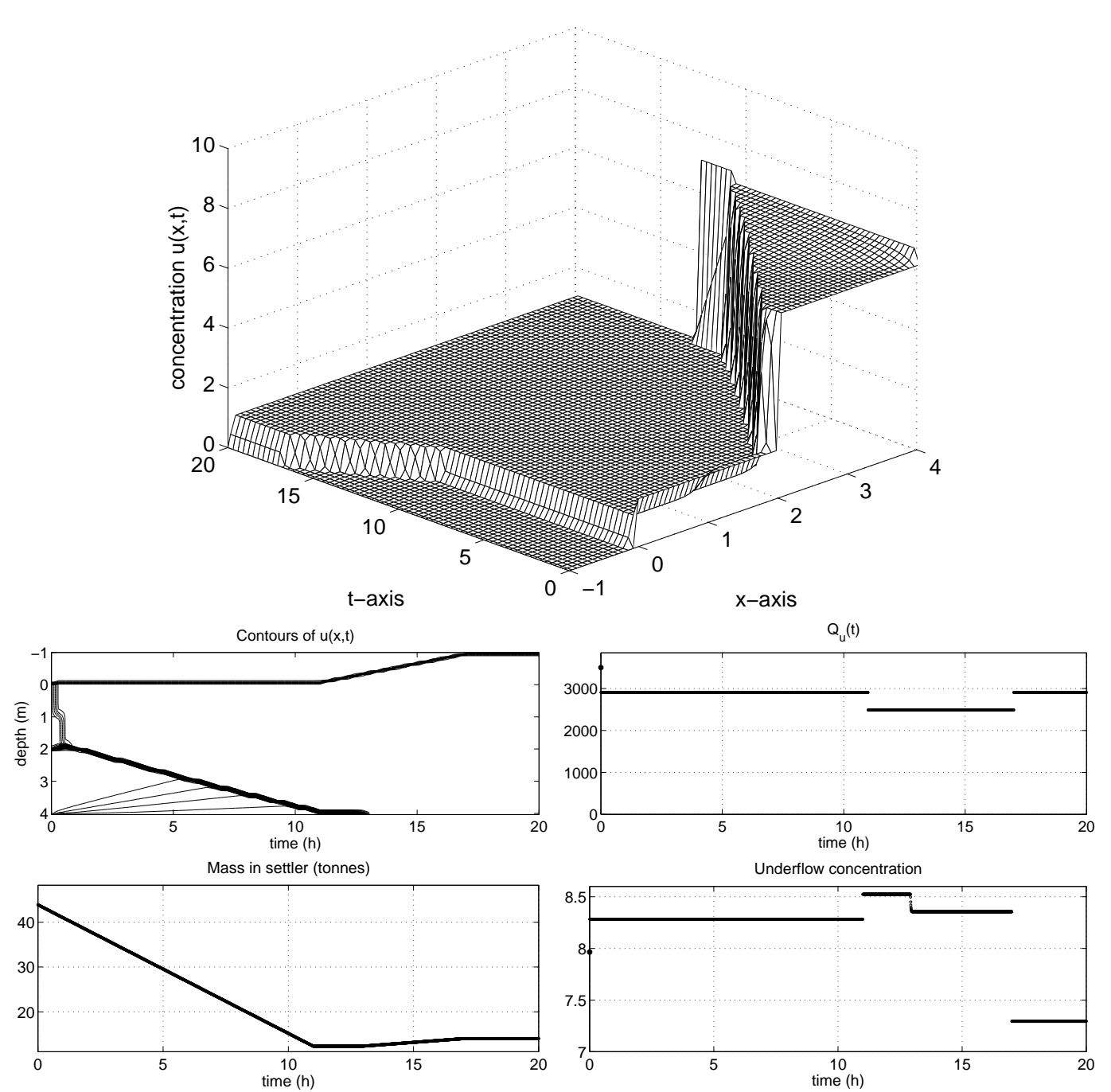

Figure 26. Optimal PCC with respect to $\mathrm{CO} 2$ and $\mathrm{CO} 3$ as $\left(u_{\mathrm{f}}, s\right)=(1,7.5) \in \mathcal{U}_{1}\left(Q_{\mathrm{u} 0}\right) \cap \Lambda_{1}$. Optimal operation is left at $t=11 \mathrm{~h}$ but $u_{\mathrm{u}}(t) \geq u_{\mathrm{u} 0}=7.96 \mathrm{~kg} / \mathrm{m}^{3}$ until $t=17 \mathrm{~h}$ instead of $t \approx 11.2 \mathrm{~h}$ as in DCL1, see Figure 15 .

\section{3. $\left(u_{\mathrm{f}}, s\right) \in \mathcal{U}_{1}\left(Q_{\mathrm{u} 0}\right) \cap\left(P \cup \Lambda_{2} \cup \Lambda_{3}\right)$}

In Sections 6.2 and 6.3 we have seen that DCL1 has a stabilizing effect on the SBL, the mass is unchanged and the underflow concentration makes a step increase directly and then stays constant. Since $\left(u_{\mathrm{f}}, s\right) \in \mathcal{S}$ there is an option to wait a while before a control action is made, see the step response in [2, Section 4.2], which shows that the underflow concentration is constant and the mass and the SBL decreases. Performing L1 at a time point $t_{\mathrm{c}}$ before the SBL reaches the bottom (which occurs at $t=T_{\mathrm{u}}=\left(m-m_{0}\right) /\left(s-s_{0}\right)$, see [2]), we obtain a new steady state with a mass and SBL both which are lower the closer $t_{\mathrm{c}}$ is to $T_{\mathrm{u}}$. The mass in the settler can actually be set to a fixed value below $m_{0}$ and above $A D u_{\mathrm{m}}$ depending on the choice of $t_{\mathrm{c}}$. This is demonstrated with a simulation in Figure 27, in which the initial data and step change are the same as in Section 6.2. To ensure that the new steady state has a 

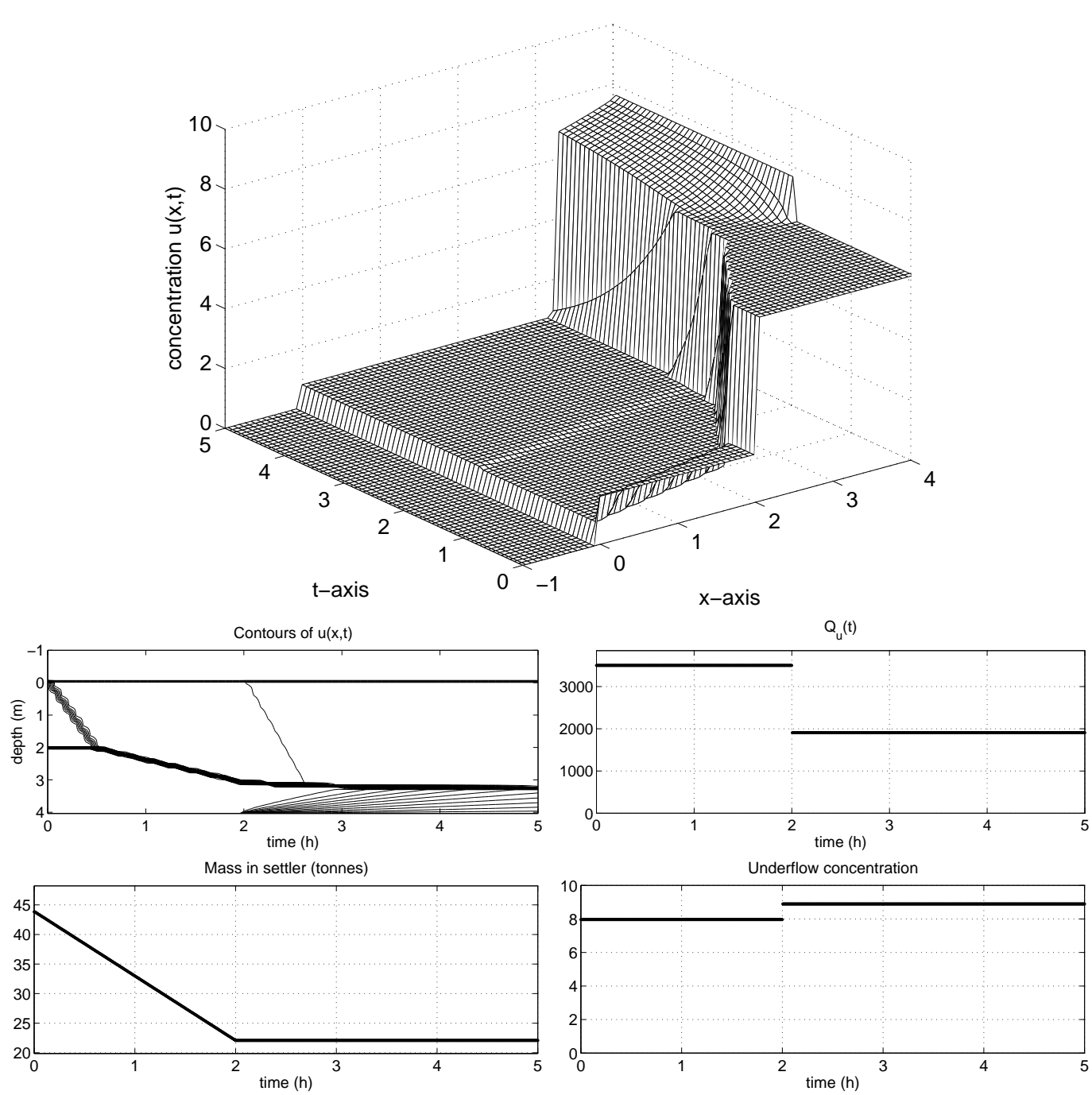

Figure 27. Optimal control with respect to $\mathrm{CO} 1, \mathrm{CO} 2$ and $\mathrm{CO} 3$ as $\left(u_{\mathrm{f}}, s\right)=(2.5,6.0) \in \mathcal{U}_{1}\left(Q_{\mathrm{u} 0}\right) \cap \Lambda_{2}$. A control action, $Q_{\mathrm{u}}=\tilde{Q}_{\mathrm{u}}=1908$, is performed at $t=t_{\mathrm{c}}=2 \mathrm{~h}$ instead of $t=0$ as in Figure 10.

SBL above the bottom, $t_{\mathrm{c}}$ cannot be too near $T_{\mathrm{u}}$, because of the transient that appears after $t_{\mathrm{c}}$. Finally, we conclude that all these control actions satisfy $\mathrm{CO} 1, \mathrm{CO} 2$ and $\mathrm{CO} 3$.

\section{4. $\left(u_{\mathrm{f}}, s\right) \in \mathcal{O}_{2 \mathrm{a}}\left(Q_{\mathrm{u} 0}\right) \cup\left(\mathcal{S}\left(Q_{\mathrm{u} 0}\right) \cap \Lambda_{3}\right)$}

If (9) is satisfied, CO1 is fulfilled by DCL1 as shown in Section 6.5. In that section we have also seen that if the sludge blanket lies close to the bottom, DCL1 may imply that optimal operation is left after a short time. This is because $Q_{\mathrm{u}}$ has been increased too much. DCL2 may be (only in the case $\left(u_{\mathrm{f}}, s\right) \in \Lambda_{3}$ ) slightly more advantageous but it is easier to wait with any control action. Even for a higher located sludge blanket a step increase in $Q_{\mathrm{u}}$ may violate $\mathrm{CO} 2$ and $\mathrm{CO} 3$, since the underflow concentration decreases directly with a step. Waiting a while before performing the control action resolves this. During the step response the mass increases initially and the SBL rises after a while, see [2, Sections 4.7-4.10]. The solution is 

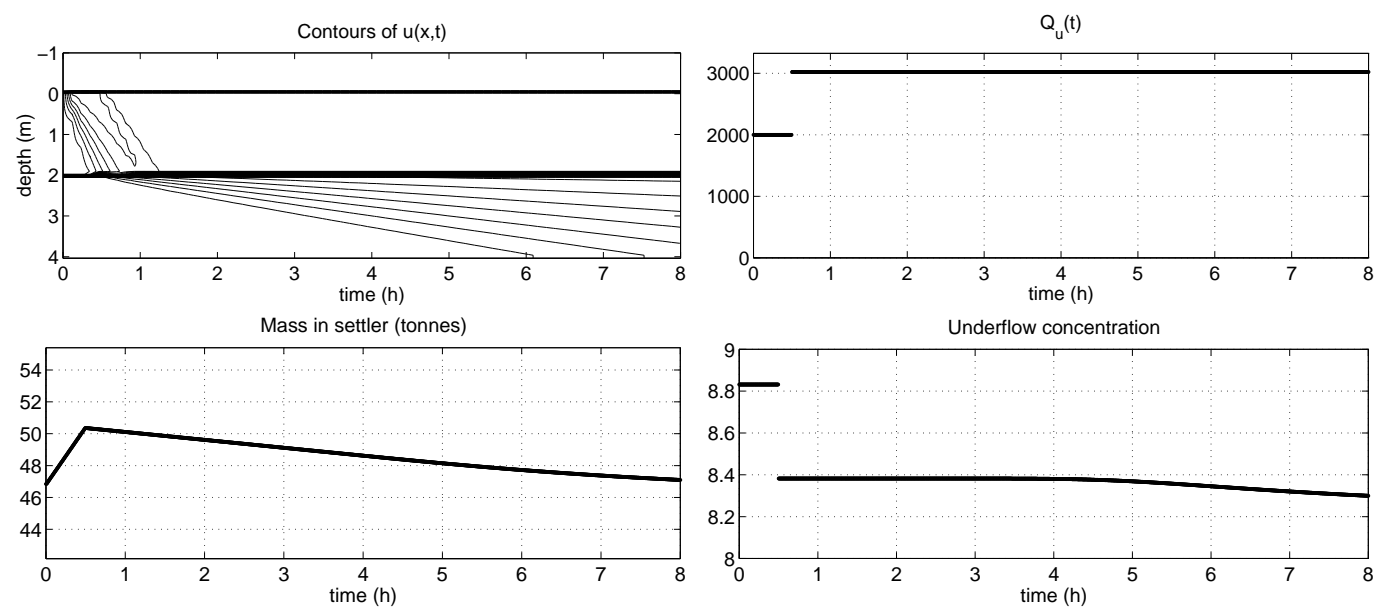

Figure 28. Optimal control with respect to $\mathrm{CO} 1$ and $\mathrm{CO} 2$ (optimal operation is maintained) as $\left(u_{\mathrm{f}}, s\right)=(5.52,8.79) \in \mathcal{O}_{2 \mathrm{a}}\left(Q_{\mathrm{u} 0}=2000\right) . Q_{\mathrm{u}}$ is set to $\tilde{Q}_{\mathrm{u}}=L_{1}^{-1}\left(u_{\mathrm{f}}, s\right)=3023$ at $t_{\mathrm{c}}=0.5 \mathrm{~h}$. Note that after 8 hours the mass and SBL are approximately the same as the initial values.
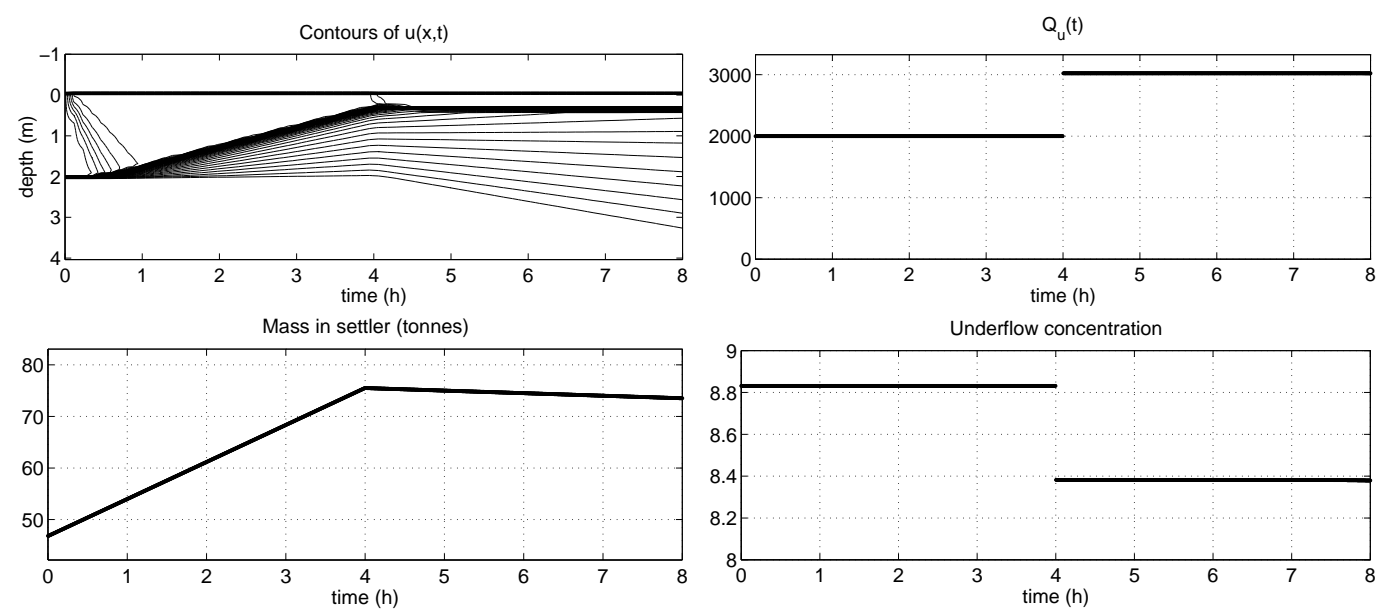

Figure 29. The same data as in Figure 28 but with $t_{\mathrm{c}}=4 \mathrm{~h}$.

qualitatively the same in all those cases up to $t=T_{\mathrm{cl}}$, which is the time point when particles start to enter the clarification zone. Performing the control action $\mathrm{L} 1$ at $t_{\mathrm{c}} \in\left(0, T_{\mathrm{cl}}\right)$, the settler remains in optimal operation. Hence both $\mathrm{CO} 1$ and $\mathrm{CO} 2$ are fulfilled. Assume that the initial data and step input are the same as in [2, Section 4.7.1]: $Q_{\mathrm{u} 0}=2000, s_{0}=6.25, u_{\mathrm{f}}=5.52$, $s=8.79$. Then $\tilde{Q}_{\mathrm{u}} \approx 3023 \mathrm{~m}^{3} / \mathrm{h}$ and simulations in the cases $t_{\mathrm{c}}=0.5 \mathrm{~h}$ and $t_{\mathrm{c}}=4 \mathrm{~h}$ $<T_{\mathrm{cl}} \approx 4.8 \mathrm{~h}$ are shown in Figures 28 and 29, respectively.

Since there is a drop in the underflow concentration at $t=t_{\mathrm{c}}, \mathrm{CO} 3$ is fulfilled by performing the L1-step just before the discontinuity reaches the effluent level, see Figure 30.

\section{5. $\left(u_{\mathrm{f}}, s\right) \in \mathcal{D}\left(Q_{\mathrm{u} 0}\right) \cap\left(\Lambda_{2} \cup \Lambda_{3 \mathrm{a}}\right)$}

Since $\left(u_{\mathrm{f}}, s\right) \in \mathcal{D}$ we know from [2, Theorem 4.1] that optimal operation is left immediately unless a direct control action $\left(Q_{\mathrm{u}}\right.$ is increased) is performed. In Section 6.5 we have seen that 


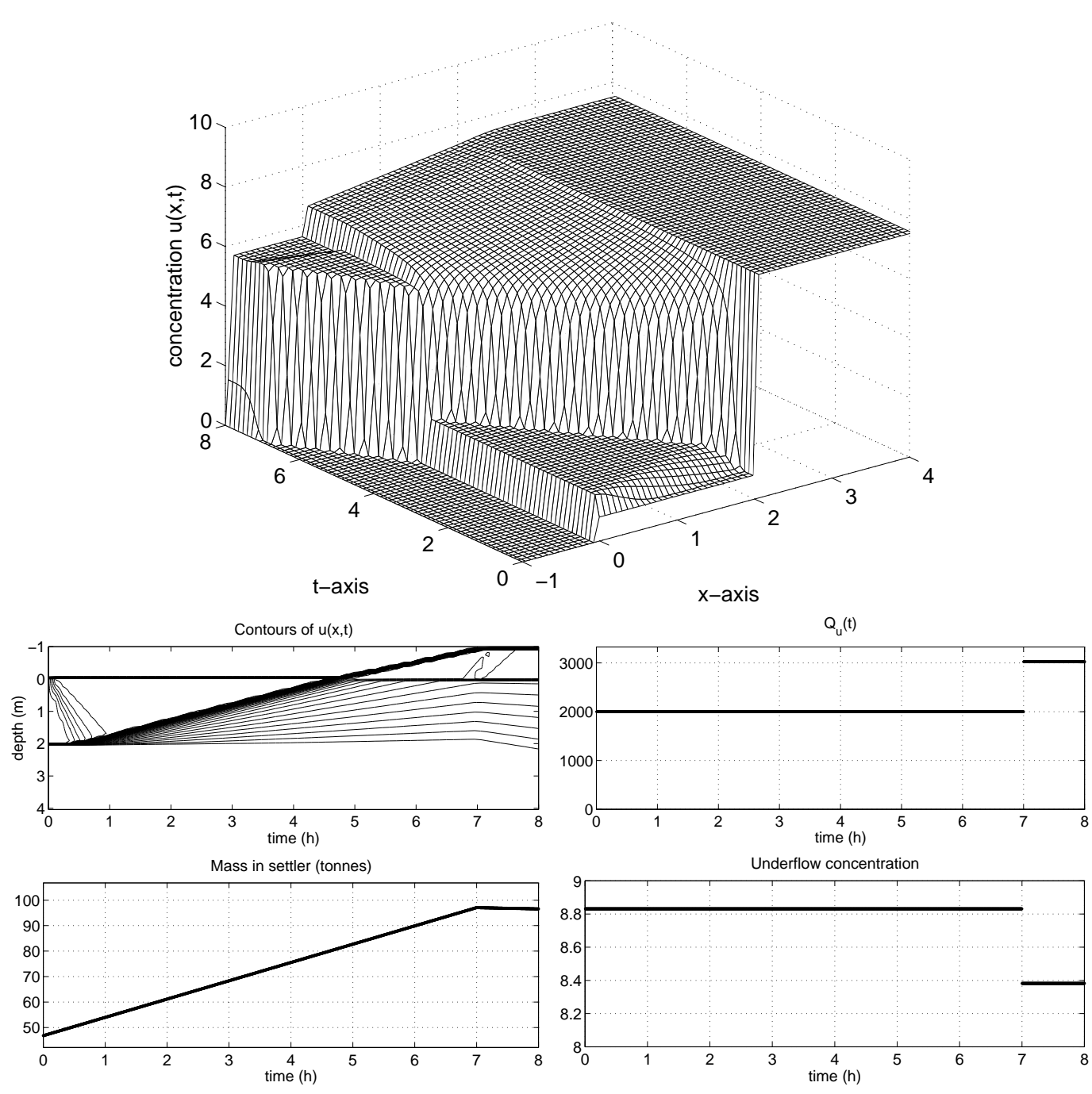

Figure 30. Initial data as in Figures 28 and 29. Optimal control with respect to CO3 with the control action L1 at $t_{\mathrm{c}}=7 \mathrm{~h}$. Note that $u_{\mathrm{e}}=0$ for $t>0$. The discontinuity in the clarification zone stays just below the top of the settler. In the new steady state the particles in the clarification zone is thus still.

if (9) is satisfied, DCL1 implies that optimal operation is maintained and an estimation of the depth of the new SBL is given by (8). Any increase in $Q_{\mathrm{u}}$ from $Q_{\mathrm{u} 0}$ will imply a decreasing SBL initially. Hence, if SBL is close to the bottom, a high value of $Q_{\mathrm{u}}$ is needed. The highest possible value (to maintain optimal operation) corresponds to a feed point on the boundary between $\mathcal{D}$ and $\mathcal{S}$, i.e., $Q_{\mathrm{u}}=L_{3}^{-1}\left(u_{\mathrm{f}}, s\right)$. Hence, strategy DCL3 will either maintain optimal operation or imply the slowest sinking SBL possible to satisfy CO1. This is demonstrated in Figure 31, where the initial data are the same as in Figure 19. If the initial depth of the SBL is slightly less, optimal operation can be maintained substantially longer by performing an L1-step at a later time point, see Figure 32.

To satisfy CO2 Theorem 4.1 yields that $Q_{\mathrm{u}}$ should be decreased to $Q_{\mathrm{u}}^{\max 1}=Q_{\mathrm{u} 0}$ as the SBL reaches the bottom. Then $u_{\mathrm{u}}=u_{\mathrm{u} 0}=u_{\mathrm{u}}^{\min }$, but there will be a rising discontinuity in 


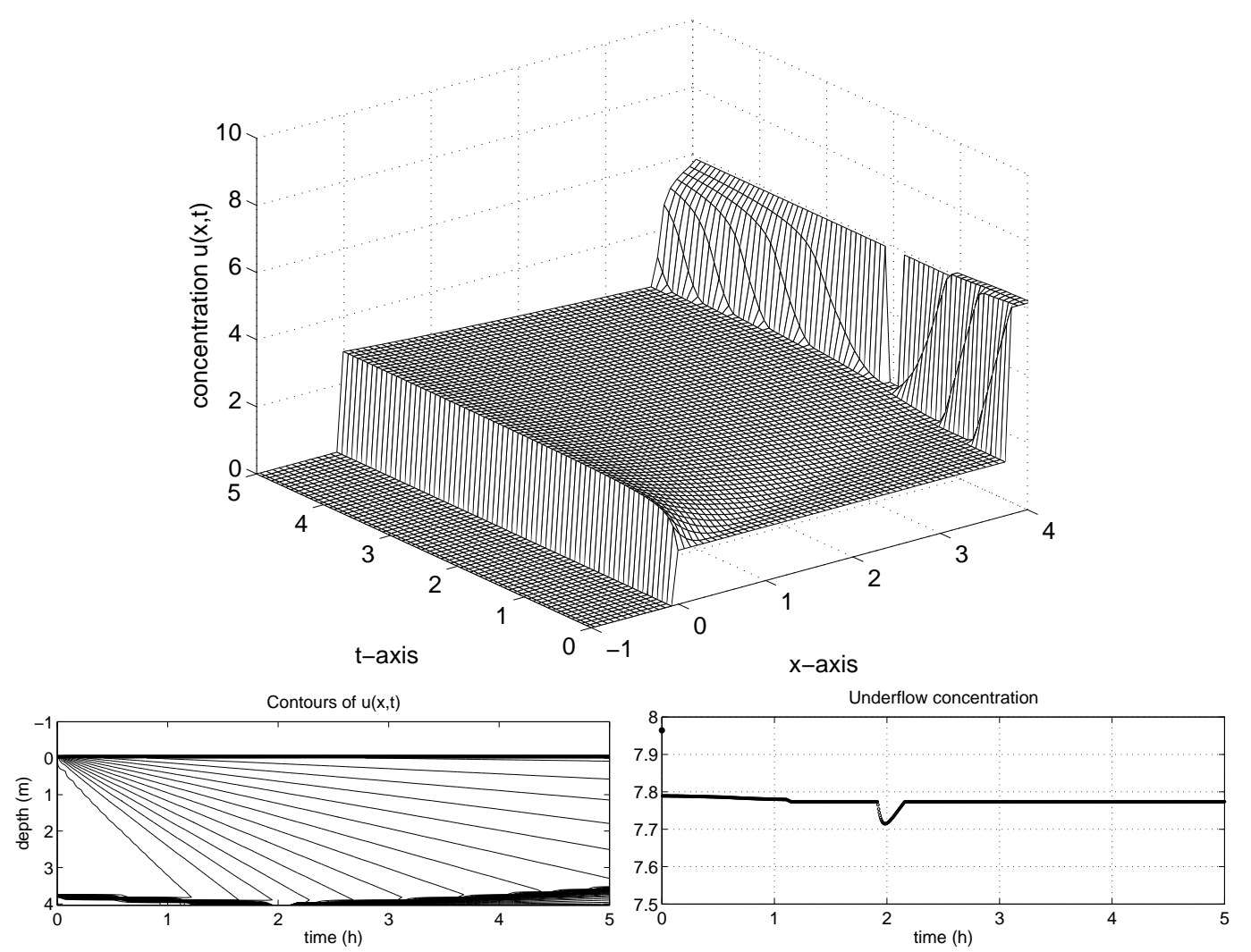

Figure 31. DCL3 with $Q_{\mathrm{u}}=3876$ in order to satisfy CO1 as $\left(u_{\mathrm{f}}, s\right)=(3,11.5) \in \mathcal{D}\left(Q_{\mathrm{u} 0}=3500\right) \cap \Lambda_{2}$ and $x_{\mathrm{sb} 0}=3.75 \mathrm{~m}$, cf. Figure 19. Optimal operation is left during a short period around $t \approx 2 \mathrm{~h}$ as the SBL reaches the bottom.

the clarification zone. Since the situation is similar to satisfying $\mathrm{CO} 3$, see below, we do not show any solution in this case.

From the proof of Theorem 4.1 we can also conclude that any step increase to $Q_{\mathrm{u}}>$ $Q_{\mathrm{u} 0}$ will directly result in a step decrease in the underflow concentration. Hence, for any $\left(u_{\mathrm{f}}, s\right) \in \mathcal{D}$, there is no control action that can result in optimal operation subject to $u_{\mathrm{u}} \geq$ $u_{\mathrm{u}}^{\mathrm{min}}$. Optimal operation must be left directly and hence $\mathrm{CO} 2=\mathrm{CO} 3$. To satisfy this objective the first control action, which is L3, has to be delayed until just before the rising discontinuity in the clarification zone reaches the effluent level, see Figure 33. After the discontinuity in the thickening zone has reached the feed level there is a small rising wave in the clarification zone, which will yield particles in the effluent unless L1 is invoked.

Now suppose that $u_{\mathrm{u}}^{\min }$ is lower than the initial value, say $7.7 \mathrm{~kg} / \mathrm{m}^{3}$. Then CO3 can be fulfilled with optimal operation until the SBL moves up into the clarification zone. Just before it reaches the effluent level the control variable is set according to L1, see Figure 34.

\section{6. $\left(u_{\mathrm{f}}, s\right) \in \Lambda_{\mathrm{a}}^{\prime}$}

From the solutions presented in [2, Sections 4.8.1 and 4.8.3] and in Section 6.7 here we can conclude that DCL1 is the optimal control action to satisfy CO1. This means that $Q_{\mathrm{u}}$ is increased to its physically maximal value for the given feed point, i.e., $Q_{\mathrm{u}}=Q_{\mathrm{f}}$. This implies that the underflow concentration makes a step decrease directly. Hence, if $u_{\mathrm{u}}^{\min }=u_{\mathrm{u} 0}$, 

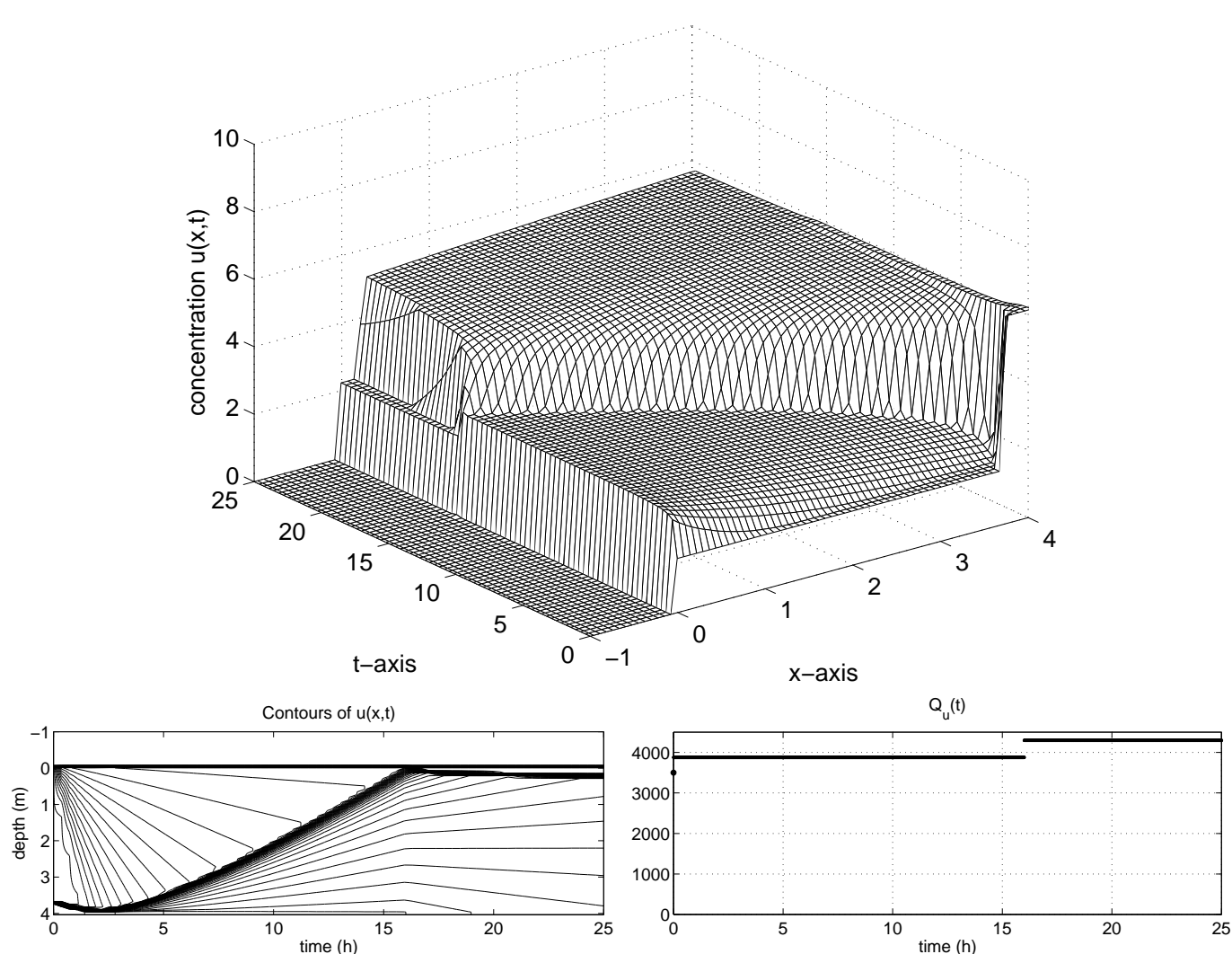

Mass in settler (tonnes)
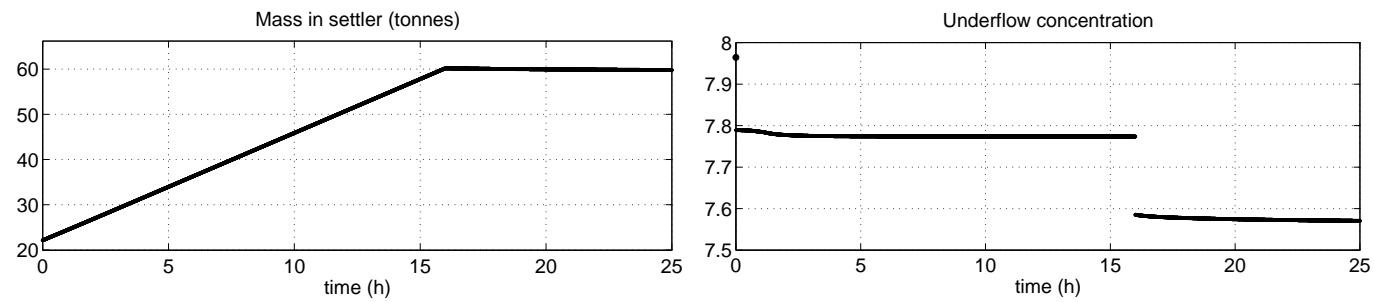

Figure 32. Optimal control with respect to $\mathrm{CO} 1$ and $\mathrm{CO} 2$ as $\left(u_{\mathrm{f}}, s\right)=(3,11.5) \in \mathcal{D}\left(Q_{\mathrm{u} 0}=3500\right) \cap \Lambda_{2}$ and $x_{\mathrm{sb} 0}=3.70 \mathrm{~m}$. DCL3 is followed by an L1-step at $t=16 \mathrm{~h}$.

then $\mathrm{CO} 2$ is not satisfied. The initial underflow concentration can be brought back by letting $Q_{\mathrm{u}}=Q_{\mathrm{u} 0}$ when the SBL reaches the feed level, provided $\left(u_{\mathrm{f}}, s\right) \in \mathcal{S}\left(Q_{\mathrm{u} 0}\right)$. This is demonstrated in Figure 35, in which we use the same numerical data as in Section 6.7. If $\left(u_{\mathrm{f}}, s\right) \in \mathcal{D}\left(Q_{\mathrm{u} 0}\right)$, then $Q_{\mathrm{u}}$ cannot be lowered to $Q_{\mathrm{u} 0}$. The lowest value in order to keep optimal operation is obtained with action L3 just before the SBL reaches the feed level or just before the rising discontinuity in the clarification zone reaches the effluent level, whichever occurs first. The solution is not substantially different from the one in Figure 35.

In order to satisfy $\mathrm{CO} 3 Q_{\mathrm{u}}$ must not be increased because of the constraint $u_{\mathrm{u}}(t) \geq u_{\mathrm{u}}^{\min }$. Hence, if $\left(u_{\mathrm{f}}, s\right) \in \mathcal{S} \cap\left(\mathcal{U}\left(Q_{\mathrm{u} 0}\right) \cup \ell_{4}\right)$, the control variable should not be changed at all. If $\left(u_{\mathrm{f}}, s\right) \in \mathcal{S} \cap \mathcal{O}\left(Q_{\mathrm{u} 0}\right)$, an L2-action is performed just before particles reach the effluent level to prevent an overflow, cf. Figure 30. If $\left(u_{\mathrm{f}}, s\right) \in \mathcal{D}$, optimal operation and $u_{\mathrm{u}}(t) \geq u_{\mathrm{u}}^{\mathrm{min}}$ cannot be satisfied together. Then $\mathrm{CO} 3$ is met by a delayed control action L2 just before overflow occurs, see Figure 36. 

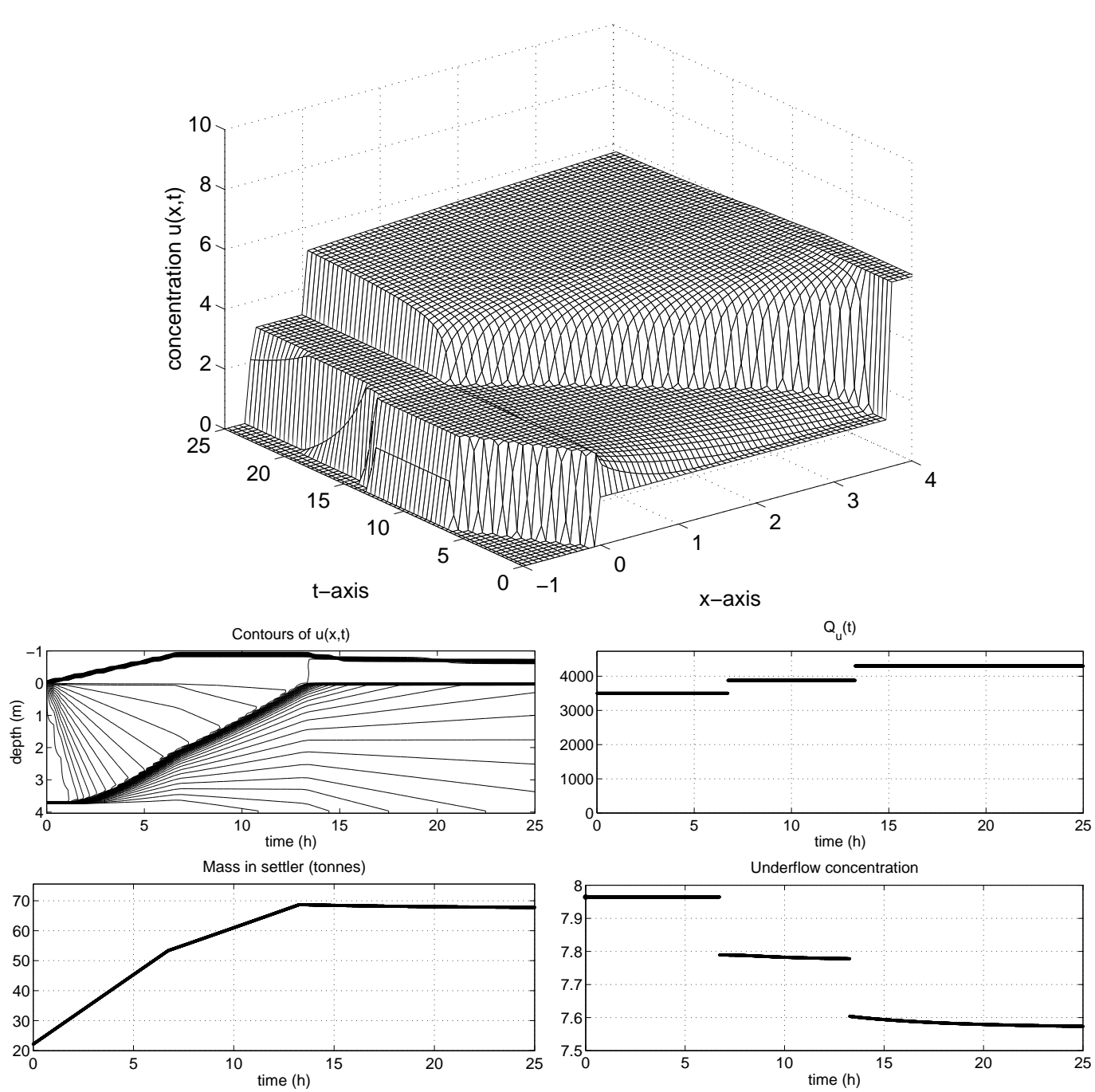

Figure 33. Optimal control with respect to $\mathrm{CO} 2$ and $\mathrm{CO} 3$ with $u_{\mathrm{u}}^{\min }=u_{\mathrm{u} 0}=7.96 \mathrm{~kg} / \mathrm{m}^{3}$ as $\left(u_{\mathrm{f}}, s\right)=(3,11.5) \in \mathcal{D}\left(Q_{\mathrm{u} 0}=3500\right) \cap \Lambda_{2}$ and $x_{\mathrm{sb} 0}=3.70 \mathrm{~m}$. Step-control actions with respect to L3 and $\mathrm{L} 1$ are performed at $t=7 \mathrm{~h}$ and $t=13.8 \mathrm{~h}$, respectively.
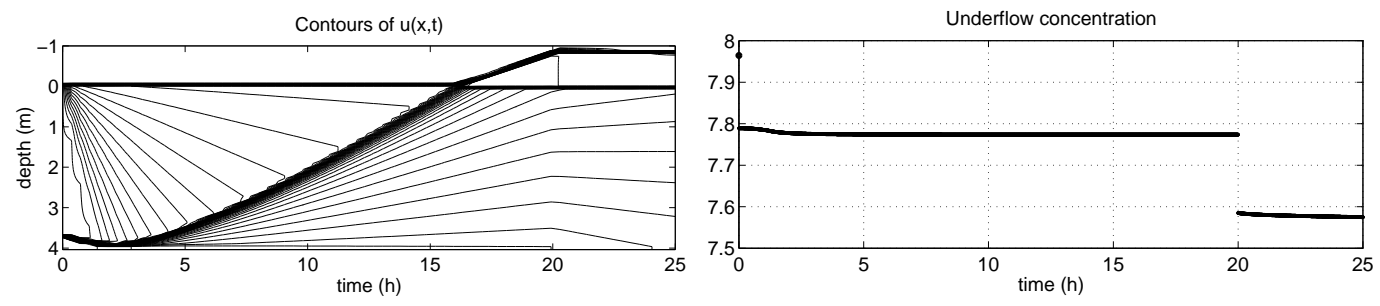

Figure 34. Optimal control with respect to $\mathrm{CO} 3$ with $u_{\mathrm{u}}^{\min }=7.7 \mathrm{~kg} / \mathrm{m}^{3}$ as $\left(u_{\mathrm{f}}, s\right)=(3,11.5) \in \mathcal{D}\left(Q_{\mathrm{u} 0}=3500\right) \cap \Lambda_{2}$ and $x_{\mathrm{sb} 0}=3.70 \mathrm{~m}$. DCL3 is followed by L1 at $t=20 \mathrm{~h}$. 

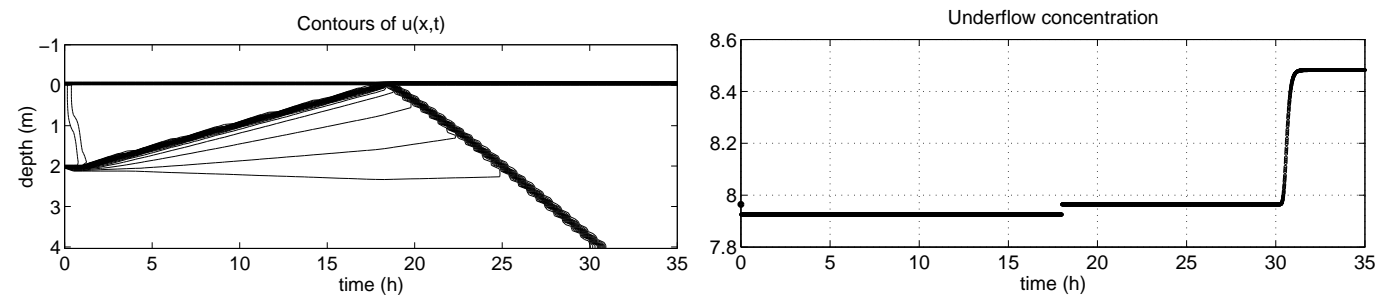

Figure 35. Optimal control with respect to $\mathrm{CO} 2$ as $\left(u_{\mathrm{f}}, s\right)=(8.3,10.5) \in \Lambda_{\mathrm{a}}^{\prime} \cap \mathcal{S}\left(Q_{\mathrm{u} 0}=3500\right)$. DCL1 with $Q_{\mathrm{u}}=Q_{\mathrm{f}}=3577$ is followed by setting $Q_{\mathrm{u}}=Q_{\mathrm{u} 0}$ at $t=18 \mathrm{~h}$.
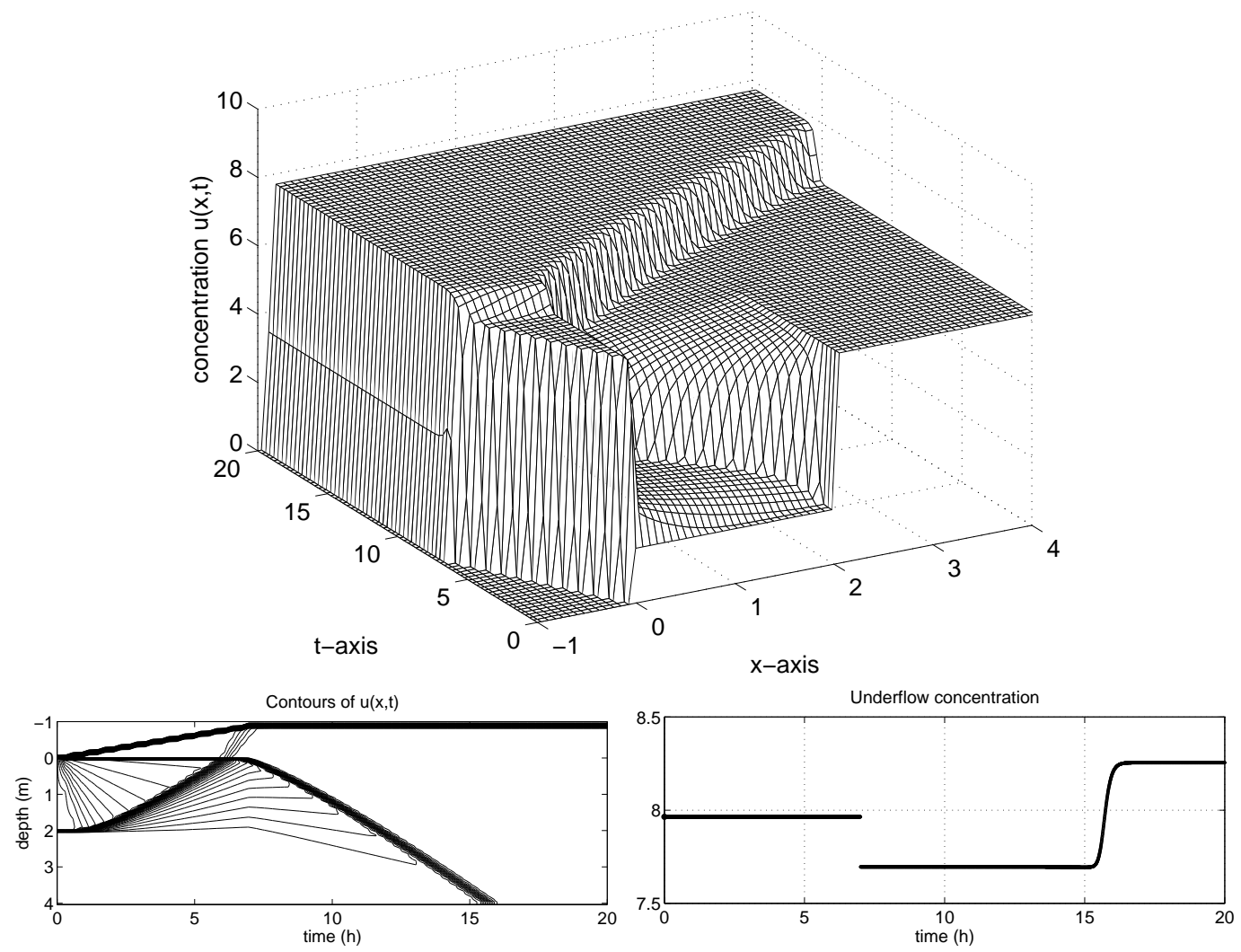

Figure 36. Optimal control with respect to $\mathrm{CO} 3$ as $\left(u_{\mathrm{f}}, s\right)=(7.7,12) \in \Lambda_{\mathrm{a}}^{\prime} \cap \mathcal{D}\left(Q_{\mathrm{u} 0}=3500\right)$. An L2-control action with $Q_{\mathrm{u}}=\tilde{Q}_{\mathrm{u}}=4110$ is performed at $t=7 \mathrm{~h}$.

\section{7. $\left(u_{\mathrm{f}}, s\right) \in \mathcal{D}\left(Q_{\mathrm{u} 0}\right) \cap \Lambda_{1 \mathrm{a}}$}

As presented in Section 6.6 DCL1 is the optimal control action to satisfy CO1, see Figure 20. Optimal operation is left as the SBL reaches the bottom. Optimal operation is inevitably left at this time point. To satisfy $\mathrm{CO} 2$ the SBL should be prevented from reaching the bottom by decreasing $Q_{\mathrm{u}}$ from its present value $\tilde{Q}_{\mathrm{u}}$. This will yield a rising discontinuity in the clarification zone, of which speed is greater the lower $Q_{\mathrm{u}}$ is. Since the concentrations above and below the sinking SBL are $u_{\mathrm{f}}$ and $u_{\mathrm{f}}^{*}$, respectively, the SBL becomes stationary for the $Q_{\mathrm{u}}$ that satisfies $S_{f}\left(u_{\mathrm{f}}, u_{\mathrm{f}}^{*}\right)=0 \Leftrightarrow f\left(u_{\mathrm{f}} ; Q_{\mathrm{u}}\right)=f\left(u_{\mathrm{f}}^{*} ; Q_{\mathrm{u}}\right) \Leftrightarrow Q_{\mathrm{u}}=-A f_{\mathrm{b}}^{\prime}\left(u_{\mathrm{f}}^{*}\right)$ (note that $Q_{\mathrm{u}}<\bar{Q}_{\mathrm{u}}$ by the definition of $\left.\Lambda_{1 \mathrm{a}}\right)$. Hence, set $Q_{\mathrm{u}}=-A f_{\mathrm{b}}^{\prime}\left(u_{\mathrm{f}}^{*}\right)$ just before the SBL reaches 

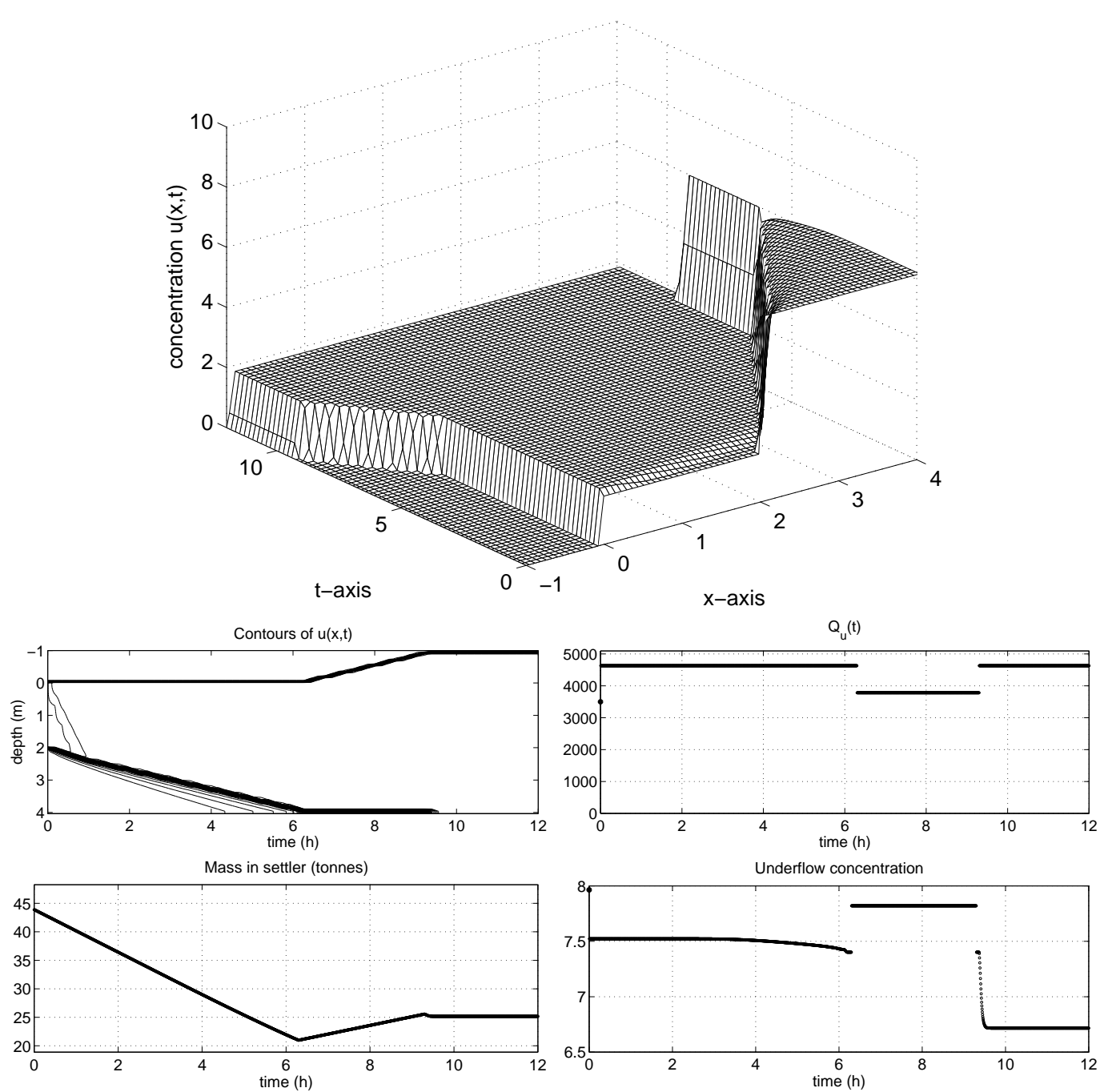

Figure 37. Optimal control with respect to $\mathrm{CO} 2$ as $\left(u_{\mathrm{f}}, s\right)=(1.8,11.0) \in \mathcal{D}\left(Q_{\mathrm{u} 0}=3500\right) \cap \Lambda_{1 \mathrm{a}}$. DCL1 with $Q_{\mathrm{u}}=\tilde{Q}_{\mathrm{u}}=4631$ is followed by $Q_{\mathrm{u}}=-A f_{\mathrm{b}}^{\prime}\left(u_{\mathrm{f}}^{*}\right)=3781$ at $t=6.3 \mathrm{~h}$ and $Q_{\mathrm{u}}=\tilde{Q}_{\mathrm{u}}$ at $t=9.3 \mathrm{~h}$.

the bottom, see Figure 37, in which we have used the same initial data as in Figure 20. To keep $u_{\mathrm{e}}=0$ we set $Q_{\mathrm{u}}=\tilde{Q}_{\mathrm{u}}$ just before an overflow occurs. To satisfy CO3 with $u_{\mathrm{u}}^{\min }=u_{\mathrm{u} 0}$ an L1-step should be performed just before the SBL reaches the effluent level, see Figure 38.

\section{8. $\left(u_{\mathrm{f}}, s\right) \in \Lambda_{1 \mathrm{~b}} \cup P_{2} \cup \Lambda_{3 \mathrm{~b}} \cup \Lambda_{\mathrm{b}}^{\prime}$}

This region is a subset of $\mathcal{D}\left(Q_{\mathrm{u} 0}\right)$, which means that $Q_{\mathrm{u}}$ must be increased so that $\left(u_{\mathrm{f}}, s\right) \in$ $\mathcal{S}\left(Q_{\mathrm{u}}\right)$, i.e., the control action $\mathrm{L} 1=\mathrm{L} 2=\mathrm{L} 3$ should be performed to prevent particles in the clarification zone. This implies that $Q_{\mathrm{u}} \geq \overline{\bar{Q}}_{\mathrm{u}}$ if $\left(u_{\mathrm{f}}, s\right) \in \Lambda_{1 \mathrm{~b}} \cup P_{2} \cup \Lambda_{3 \mathrm{~b}}$ (see Sections 6.5 and 6.6) and $Q_{\mathrm{u}}=Q_{\mathrm{f}}$ for $\left(u_{\mathrm{f}}, s\right) \in \Lambda_{\mathrm{b}}^{\prime}$ (see Section 6.8). In both cases optimal operation is left immediately. As is demonstrated in those sections DCL1 (= DCL2 = DCL3) implies CO1 $\left(u_{\mathrm{cl}}=0\right)$. Furthermore, $\mathrm{CO} 2$ and $\mathrm{CO} 3$ are equal. To satisfy these objectives, i.e., maintaining 

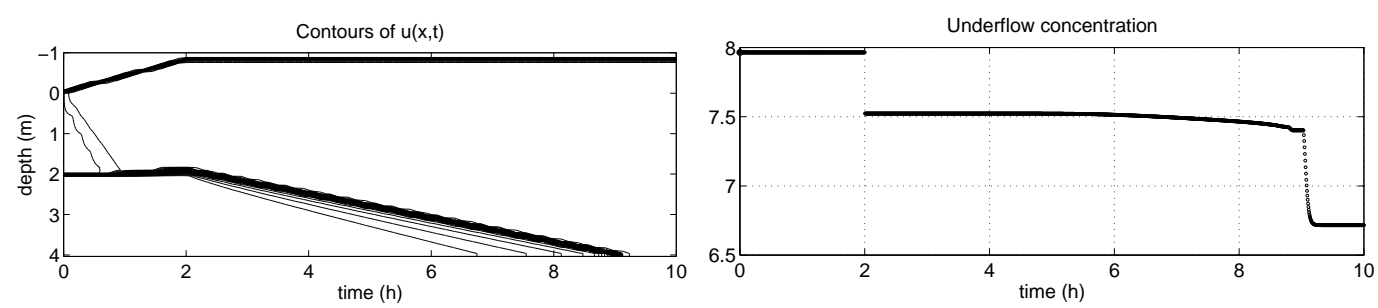

Figure 38. Optimal control with respect to $\mathrm{CO} 3$ as $\left(u_{\mathrm{f}}, s\right)=(1.8,11.0) \in \mathcal{D}\left(Q_{\mathrm{u} 0}=3500\right) \cap \Lambda_{1 \mathrm{a}}$. The control action L1 with $Q_{\mathrm{u}}=\tilde{Q}_{\mathrm{u}}=4631$ is performed at $t=2 \mathrm{~h}$.

$u_{\mathrm{u}}=u_{\mathrm{u}}^{\min }=u_{\mathrm{u} 0}$ as long as possible, the first step-control action (L1 = L2 $=\mathrm{L} 3$ ) should be taken just before the SBL reaches the effluent level to keep $u_{\mathrm{e}}=0$.

\section{Conclusions}

The main purposes of a clarifier-thickener unit is that it should produce a high underflow concentration and a zero effluent concentration. The main difficulty in the control of an ideal clarification-thickening process is that it is non-linear with complex relations between concentrations and volume flows via the solution of a partial differential equation. The input variable is the feed point $\left(u_{\mathrm{f}}, s\right)$ consisting of the feed concentration and flux. The control variable is the volume flow $Q_{\mathrm{u}}$ of the underflow stream.

In order to approach the control problem, control objectives are defined in Section 4. In these, the concept of optimal operation is fundamental. This relates to a specific type of solution of the model partial differential equation, where there is a sludge blanket level (SBL), which is a discontinuity in the thickening zone separating low and high concentrations. Theorem 4.1 states that during optimal operation the underflow concentration can be kept above a given lower bound by keeping the control variable $Q_{\mathrm{u}}$ less than a specific value, which depends on the bound. This value can be obtained graphically in the operating chart for control of steady states, see Figure 4, which also shows the interval of possible underflow concentrations during optimal operation. Based on the knowledge about the control of steady-state solutions in [1] and the step responses in [2], control strategies are introduced in Section 5. They state how the control variable $Q_{\mathrm{u}}$ should be set as a function of the feed point and time to meet each control objective.

In this paper we focus on the control of the process for each possible step input and with respect to three control objectives. The first stage is to investigate the responses when a single step-control action is performed directly. The control variable is set to a value corresponding to a desired steady state (if possible optimal operation, otherwise a critically loaded settler). Such responses are classified in Section 6, where the operating chart in Figure 6 is divided into seven regions corresponding to the qualitatively different solutions. Unfortunately, it turns out that this single-step strategy is not always sufficient to satisfy the control objectives. For example, if the initial SBL is located near the bottom of the vessel and there is (even a small) step input change such that the settler is going to be overloaded, then a direct control action may imply that optimal operation is left after a short time as the SBL reaches the bottom, see Figure 19.

The main results of the paper are the optimal control strategies presented in Section 7 by means of the operating chart in Figure 25 and the accompanying Table II. This chart also 
contains seven regions, which, however, are different from the previous ones (Figure 6). An overall conclusion is that, for any step input, piecewise constant control with at most three step-control actions is sufficient to meet any of the control objectives.

All theoretically possible feed concentrations have been considered. In reality, only lower or intermediate feed concentrations are of interest. It is therefore interesting to note that for feed concentrations in an arbitrary small interval around the characteristic concentration $u_{\mathrm{m}}$ five of the seven regions of the optimal-control chart in Figure 25 are possible. This really illustrates the non-linearity of the process and the difficulty in controlling it.

For all step responses with unchanged $Q_{\mathrm{u}}$ the underflow concentration and the solution in the bottom part of the thickening zone are unchanged until possibly the SBL reaches the bottom (see [2]). All solutions in Section 6 can be regarded as step responses when also $Q_{\mathrm{u}}$ makes a jump. An interesting conclusion is then that the underflow concentration always makes a jump at $t=0$ but the solution in the bottom part of the thickening zone changes only continuously until possibly the SBL reaches the bottom.

For intermediate feed concentrations and the two most common step inputs, the following can be concluded referring to the optimal-control chart in Figure 25. Firstly, if $\left(u_{\mathrm{f}}, s\right) \in$ $\mathcal{U}_{1} \cap\left(P \cup \Lambda_{2} \cup \Lambda_{3}\right)$, the settler is prevented to be underloaded by lowering the control variable $Q_{\mathrm{u}}$. It turns out that has a stabilizing effect on the SBL, the mass is unchanged and the underflow concentration makes a step increase directly and then stays constant. An explicit relation between the initial and the new SBL is given, see (6) and Figure 9. Secondly, if $\left(u_{\mathrm{f}}, s\right) \in \mathcal{O}_{2 \mathrm{a}} \cup\left(\mathcal{S} \cap \Lambda_{3}\right)$, the prevention of an overloaded settler is obtained by increasing $Q_{\mathrm{u}}$. The sludge blanket declines initially and may reach the bottom if the initial depth is too low, see Figure 19. A safe margin is given by the inequality (9). Even for an initially higher SBL a step increase in $Q_{\mathrm{u}}$ may be disadvantageous since the underflow concentration decreases directly with a step and this may violate the given control objective. To satisfy the control objectives, one should wait a while with any control action, see Figures 28-30. In this case the initial SBL can actually be recovered with only one control action, see Figure 28.

A natural continuation of this series of papers is to generalize the results on step responses and control of these to a dynamic input and to present a regulator for the process.

The results presented in this series of papers have been obtained for ideal non-flocculated suspensions that obey Kynch's assumption. Many real slurries consist of flocculated suspensions that show a compressible behaviour at high concentrations and it would be interesting to see how the present results alter when compression is taken into account. The model equation will then have an additional diffusion term, which is non-zero only for concentrations above a critical concentration. Extensive analyses of such a strongly degenerate parabolic equation have been performed the last few years and, what concerns the modelling of continuous sedimentation in clarifier-thickener units, culminated in the new paper [12] by Bürger et al.

\section{Acknowledgement}

I am grateful to Dr Anders Holst, Centre for Mathematical Sciences, Lund University, for reading and commenting upon parts of the manuscript. 


\section{References}

1. S. Diehl. Operating charts for continuous sedimentation I: Control of steady states. J. Eng. Math., 41:117144,2001

2. S. Diehl. Operating charts for continuous sedimentation II: Step responses. To appear in J. Eng. Math.

3. H. Stehfest. An operational dynamic model of the final clarifier. Trans. Inst. Meas. Control, 6(3):160-164, 1984.

4. T. M. Keinath. Operational dynamics and control of secondary clarifiers. J. Water Pollut. Control Fed., 57(7):770-776, 1985.

5. M. C. Bustos, F. Paiva, and W. Wendland. Control of continuous sedimentation as an initial and boundary value problem. Math. Methods Appl. Sci., 12:533-548, 1990.

6. N. G. Barton, C.-H. Li, and J. Spencer. Control of a surface of discontinuity in continuous thickeners. J. Austral. Math. Soc. Ser. B, 33:269-289, 1992.

7. P. Balslev, C. Nickelsen, and A. Lynggaard-Jensen. On-line flux-theory based control of secondary clarifiers. Wat. Sci. Tech., 30(2):209-218, 1994.

8. J.-Ph. Chancelier, M. Cohen de Lara, and F. Pacard. Analysis of a conservation PDE with discontinuous flux: A model of settler. SIAM J. Appl. Math., 54(4):954-995, 1994.

9. J.-Ph. Chancelier, M. Cohen de Lara, C. Joannis, and F. Pacard. New insight in dynamic modelling of a secondary settler - II. Dynamical analysis. Wat. Res., 31(8):1857-1866, 1997.

10. S. Diehl. A conservation law with point source and discontinuous flux function modelling continuous sedimentation. SIAM J. Appl. Math., 56(2):388-419, 1996.

11. S. Diehl and U. Jeppsson. A model of the settler coupled to the biological reactor. Wat. Res., 32(2):331-342, 1998.

12. R. Bürger, K. H. Karlsen, and J. D. Towers. A model of continuous sedimentation of flocculated suspensions in clarifier-thickener units. To appear in SIAM. J. Appl. Math. 